Federal Reserve Bank of Minneapolis

Research Department

\title{
A Model of Bimetallism
}

\author{
François R. Velde and Warren E. Weber
}

Working Paper 588

August 1998

\begin{abstract}
Bimetallism has been the subject of considerable debate: Was it a viable monetary system? Was it a desirable system? In our model, the (exogenous and stochastic) amount of each metal can be split between monetary uses to satisfy a cash-in-advance constraint, and nonmonetary uses in which the stock of uncoined metal yields utility. The ratio of the monies in the cash-in-advance constraint is endogenous. Bimetallism is feasible: we find a continuum of steady states (in the certainty case) indexed by the constant exchange rate of the monies; we also prove existence for a range of fixed exchange rates in the stochastic version. Bimetallism does not appear desirable on a welfare basis: among steady states, we prove that welfare under monometallism is higher than under any bimetallic equilibrium. We compute welfare and the variance of the price level under a variety of regimes (bimetallism, monometallism with and without trade money) and find that bimetallism can significantly stabilize the price level, depending on the covariance between the shocks to the supplies of metals.
\end{abstract}

Keywords: bimetallism, monometallism, double standard, commodity money

*Velde, Federal Reserve Bank of Chicago; Weber, Federal Reserve Bank of Minneapolis and University of Minnesota. We thank without implicating Marc Flandreau, Ed Green, Angela Redish, and Tom Sargent. The views expressed herein are those of the authors and not necessarily those of the Federal Reserve Bank of Chicago, the Federal Reserve Bank of Minneapolis, or the Federal Reserve System. 


\section{Introduction}

Until the 20th century, most countries used some form of commodity money. Usually, the commodities were metal, gold and silver, in the shape of coins. A monetary regime which tries to maintain concurrent circulation of coins made of both metals at a fixed exchange rate is called bimetallism.

Bimetallism has the been the subject of considerable debate. Much of it occurred in the 19th century (Darwin 1898, Fisher 1911, Giffen 1892, Laughlin 1896, Shaw 1894, Willis 1901), and has been revived recently (Chen 1972, Garber 1986, Friedman 1990a, 1990b; Redish 1990, 1995; Oppers 1995, 1996; Dowd 1996; Flandreau 1996, 1997). Many issues raised in the debate fall under two broad questions. The first concerns existence: Is bimetallism implementable, sustainable, stable? Defenders of bimetallism maintain that concurrent circulation of gold and silver is possible for long periods of time under a wide range of circumstances and that the setting of a legal ratio between gold and silver coins acts to stabilize the market price of the (uncoined) metals around this ratio. The opponents of bimetallism maintain that concurrent circulation is not possible and that bimetallism will, in reality, boil down to a knife-edge alternation between gold and silver monometallic standards, as the market ratio moves above and below the legal ratio. The second question concerns welfare properties: Is bimetallism desirable? The proponents claim that bimetallism reduces fluctuations in the price level due to shocks to the supplies of the metals. The opponents counter that any such benefits are small compared to the costs involved in constantly switching between single standards.

At a theoretical level, the debate is unsettled, primarily because there currently is no fully developed model of commodity money regimes in which these questions can be directly answered. Models of commodity money have been proposed by Barro (1978), Sargent and Wallace (1983), and Sargent and Smith (1997). Models of bimetallism have been constructed by Chen (1972), Dowd (1996), and Flandreau (1996). All three of these models analyze bimetallism in a general equilibrium setting that permits both monetary and nonmonetary uses for both metals. All three also obtain bounds on the legal ratio necessary for concurrent circulation of the two metals. However, none of 
them has a fully articulated structure and none analyzes the behavior of bimetallism under uncertainty.

Chen assumes ad hoc demand functions for the nonmonetary uses of the metals and obtains the monetary demands from a cash-in-advance constraint similar to the one we use. However, he does not explicitly have a mint in the model, so that he cannot analyze the effects of seigniorage on the workings of a bimetallic regime. Dowd has a structure similar to Chen's except that rental rates on the metals enter the nonmonetary demand functions and the CIA constraint, instead of the prices of metals. Flandreau also has a structure, demand functions, and CIA similar to Chen. His analysis has three countries, two of which are monometallic with different metals.

Our model modifies the cash-in-advance models of Sargent and Smith (1997) and Sargent and Velde (1997) by introducing "jewelry," that is, alternative uses for gold and silver. The total amount of each metal, which is exogenous and stochastic, can be split between monetary and nonmonetary uses. Agents derive utility from the stocks of the metals not in monetary use. The two forms of money are substitutable in the cash-in-advance constraint at a rate that is endogenous but given to the consumer. We formally prove the existence of a continuous range of possible ratios, with corresponding allocations of metal between jewelry and money, and corresponding relative price of the two metals (market ratio). There is thus a continuum of Pareto-rankable equilibria, rather than the indeterminacy characteristic of multiple fiat money models (Kareken and Wallace 1980). This multiplicity has not been formally emphasized. We identify the condition under which bimetallism gives way to monometallism, and by what process. We numerically analyze the response of bimetallism to shocks (which are equivalently viewed as supply or demand shocks) to the metals. We compute equilibria and study the variability of the price level under alternative monetary arrangements and for various structure of the stochastic processes affecting the stocks of metals. We also compute welfare under the different standards for both the certainty and the uncertainty case.

The model formally confirms some of the views of the defenders of bimetallism. Concurrent circulation is viable over long periods without changes in the legal ratio: given a legal ratio, stocks of jewelry and coins will adjust in the face of supply or 
demand shocks to maintain equality with the market ratio. This mechanism operates as long as there are positive stocks of both coins. Further, bimetallism does provide a more stable price level, and the reduction in the variance of the price level depends, as one would expect, on the correlation between gold shocks and silver shocks.

However, we have not been unreservedly converted to bimetallism. The literature had not considered welfare under various regimes. We find that, for preferences displaying constant elasticity of substitution between the metals, a single standard always yields higher welfare than bimetallism. The computations show that the welfare loss from bimetallism is significant, and not outweighed by its 'smoothing' action.

The paper proceeds as follows. In the next section we present some preliminaries for understanding issues involved in analyzing bimetallism. Specifically, we provide some definitions, summarize the relevant history, and give a more complete exposition of the debate over bimetallism. In the second section we present the general equilibrium model with two metals and demand for jewelry for a single (world) country. The third section analyzes the case with no seigniorage: we consider existence and welfare in the certainty case, as well as in the case where the metals are subject to separate supply and demand shocks. The fourth section analyzes the case with seigniorage under certainty. We then conclude. 


\section{Preliminaries}

\section{Definitions}

We begin by clarifying some of the terminology involved in the discussion of commodity monies.

Countries can adopt a variety of institutional arrangements to promote the use of particular commodities as money; the outcome of those arrangements can vary as well. A country's regime can be characterized by its underpinning institutions (de jure) or by the observed outcome (de facto).

The institutions revolve around two main elements: the minting laws and the legal tender laws. The country can provide for free minting of one metal or both. "Free" minting usually means unrestricted, not free of charge: the mint, either governmentrun or leased, stands ready to convert metal into coin at a set mint price, expressed as $N$ coins per kilogram of metal. It was often the case that minting was free but $N$ coins weighed $1-\sigma \mathrm{kg}, \sigma>0$ being the seigniorage rate. The case $\sigma=0$ is called gratuitous minting. Free minting of at least one metal is a requirement of a commodity money regime. Free minting of both metals is a necessary, but not sufficient condition for bimetallism. ${ }^{1}$

Legal tender laws define the unit of account in which prices and debt contracts are expressed, and state which coins are legal tender for debts so denominated, for how many units each coin is tendered, and, possibly, some form of limit on how many coins of a given type can be tendered. ${ }^{2}$ In the absence of such such a limit, the coin is said to have unlimited legal tender.

If both gold and silver have unlimited legal tender at a fixed rate and both are freely minted, the regime is called a de jure bimetallic or double standard. This system was in place in several countries in the 19th century, notably the United States and

\footnotetext{
1 In practice, many intermediate cases were found, for example with the mint offering to convert at most a fixed amount of metal per day (restricted minting).

2 The limit can be a number of coins, or a share of the amount tendered.
} 
the Latin Union comprising France. The other three possible cases comprise different forms of monometallism. If only one metal is freely minted and has unlimited legal tender, then the regime is strict monometallism. England was on such a standard, based on gold, from 1816. A regime in which both metals are legal tender but only one is freely minted is called a limping standard (or a hunchback standard by Walras). This was the regime in place in several countries after their move to the gold standard: England from 1774 to 1816, France, Germany and the United States after 1873. A variant is the system adopted in India after 1893. India went on the gold standard but without a gold coinage; instead, the government bought and sold silver rupees for (gold-based) British pounds at a fixed rate. In the third case, in which both metals are freely minted but only one is legal tender, the coin without legal tender is called a trade money, and its value in units of account is freely set by the market. This was the typical regime in Medieval Europe, and also the regime in place in Germany, Austria and the Netherlands until their move to the gold standard: the gold coin floated in terms of the silver coin.

It is usually understood that the aim of a de jure bimetallic standard is to ensure concurrent circulation of both metals at a fixed rate. The outcome may be different, and a de jure bimetallic regime may be a de facto monometallic regime. Concurrent circulation may fail, as in England until 1774, where in practice only gold was minted and circulated; or Mexico until 1905, where only silver circulated. Alternatively, parity of both metals at the legal rate may fail when official legal tender laws are ignored, and one of the coins is, de facto, a trade coin. Prussia, in the $1820 \mathrm{~s}$, attempted without success to enforce a fixed rate for its gold coin.

\section{The History}

This section briefly sketches the types of regimes adopted by various countries. In Europe, since the High Middle Ages, silver had always been the basis of the monetary system, and silver coins or fixed quantities of silver coins (dozens, scores of dozens) were the units of account in which debts and prices were expressed. In the 13th century gold coins, which had remained in use in Byzantium and the Muslim world, reappeared in Western Europe. In the Middle Ages, gold coins fluctuated in value in terms of silver 
coins. For example, there are daily records of the market value of the gold fiorino in Florence in the 14th century. Minting institutions, which took shape early, remained roughly unchanged for centuries: in principle, mints stood ready to convert bullion into coins at posted prices, always charging seigniorage.

By the 16th century, European governments commonly ascribed legal tender values to gold coins, and worried about the appropriate ratio to set between the legal tender value of a weight of gold and that of the same weight of silver (the so-called legal ratio). It did not escape their attention, however, that the ratio of the market price of a weight of gold to that of the same weight of silver (the so-called market ratio) varied over time, and that legal ratios varied across European countries and over time.

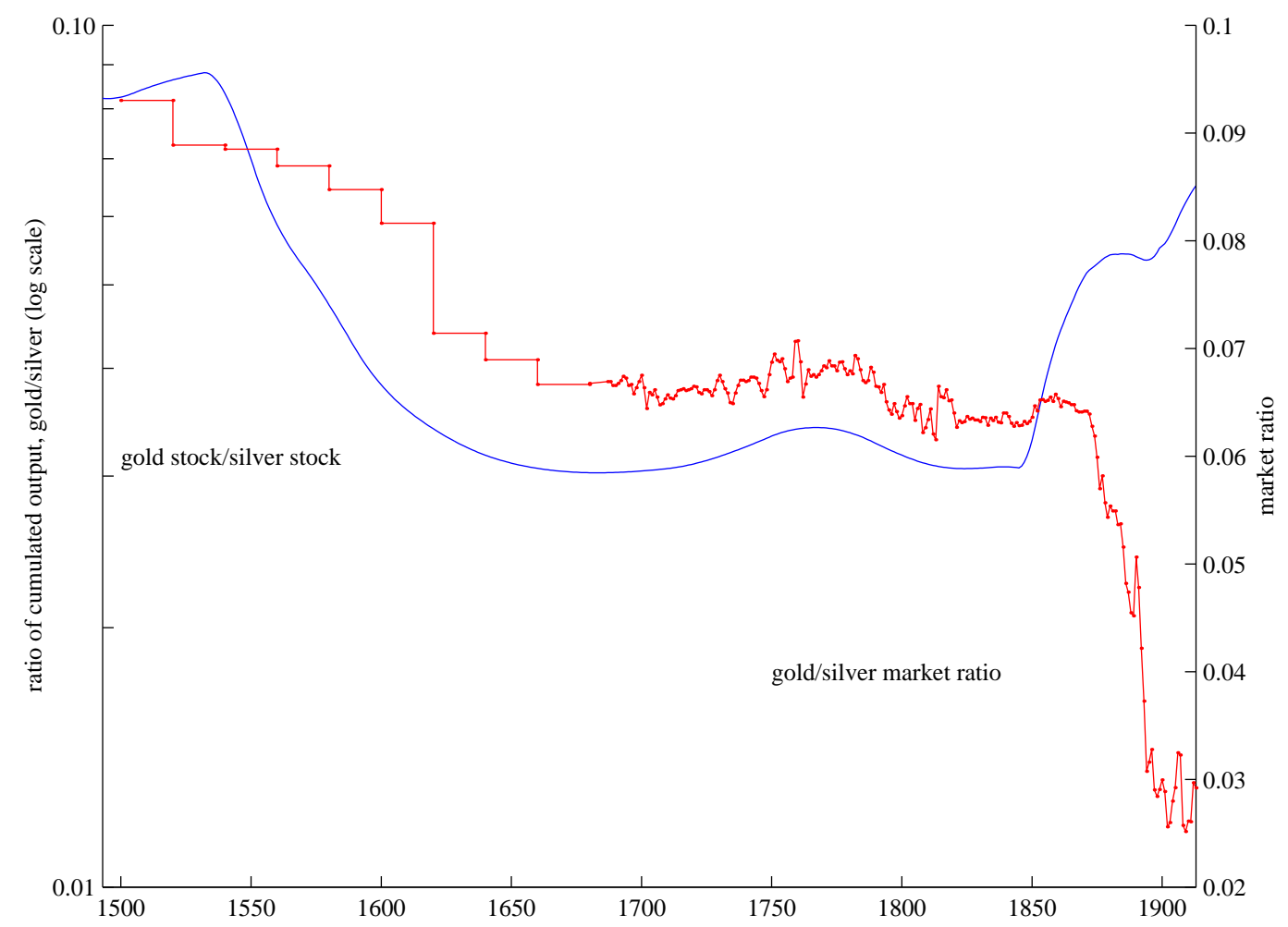

Figure 1: Ratio of gold to silver world stocks (left scale, log) and market ratio of silver to gold (right scale). The market ratio series is only a true market observation after 1687. See Appendix 2 for sources.

Figure 1 plots the market ratio from 1492 to 1913, and compares it with the es- 
timated ratio of the world stocks of gold and silver. It suggests that secular movements in the latter accompanied changes in the former. Countries found that, if they wanted to maintain a double standard (and not all did), they had to adjust the legal ratio at some times.

By the 18th century, a wide variety of monetary arrangements had arisen across Europe in response to these difficulties. England was on a de facto gold standard since 1717, and a limping standard since 1774. Spain, Italy and France maintained bimetallism (albeit at slightly different rates), and in 1792 the nascent United States adopted bimetallism as well. On the other hand, Germanic, Scandinavian and Slavic Europe had maintained or returned to medieval silver monometallism, in some cases with gold as trade money. The East (India and China) was on silver. After the French Revolutionary and Napoleonic Wars (1792-1816), the situation remained much the same until the 1870s, except that all European bimetallic countries were all at or near the French legal ratio of 15.5, while the United States was on de jure bimetallism at a ratio of 15 until 1837 and 16 thereafter.

The gold discoveries of California (1848), Australia (1851), South Africa (1885) and the introduction of the cyanide process (1887) induced major disturbances in the world bullion markets, and reversed the production trend of the previous centuries in favor of gold, as shown in Figure 1 and Figure 2. Soon, debates flourished over the choice of a standard. (See the bibliography assembled by Dana S. Horton, U.S. Senate 1879, 737-78.) An international monetary conference in 1867 endorsed the gold standard.

In 1871, unified Germany decided to switch from the silver standard to the gold standard. In 1873, many European bimetallic countries suspended free minting of silver, and by 1876 all had adopted the gold standard. In 1893, India suspended free minting of silver, leaving China as the sole major country not on the gold standard. Figure 3 shows the countries with free coinage of silver, as well as the countries with free coinage of gold and legal tender laws for gold, as a share of gross world output from 1820 to 1913. Against the right-hand scale is plotted the silver/gold ratio over the same period. It is apparent that the switch away from silver and bimetallism was 
abrupt and widespread.

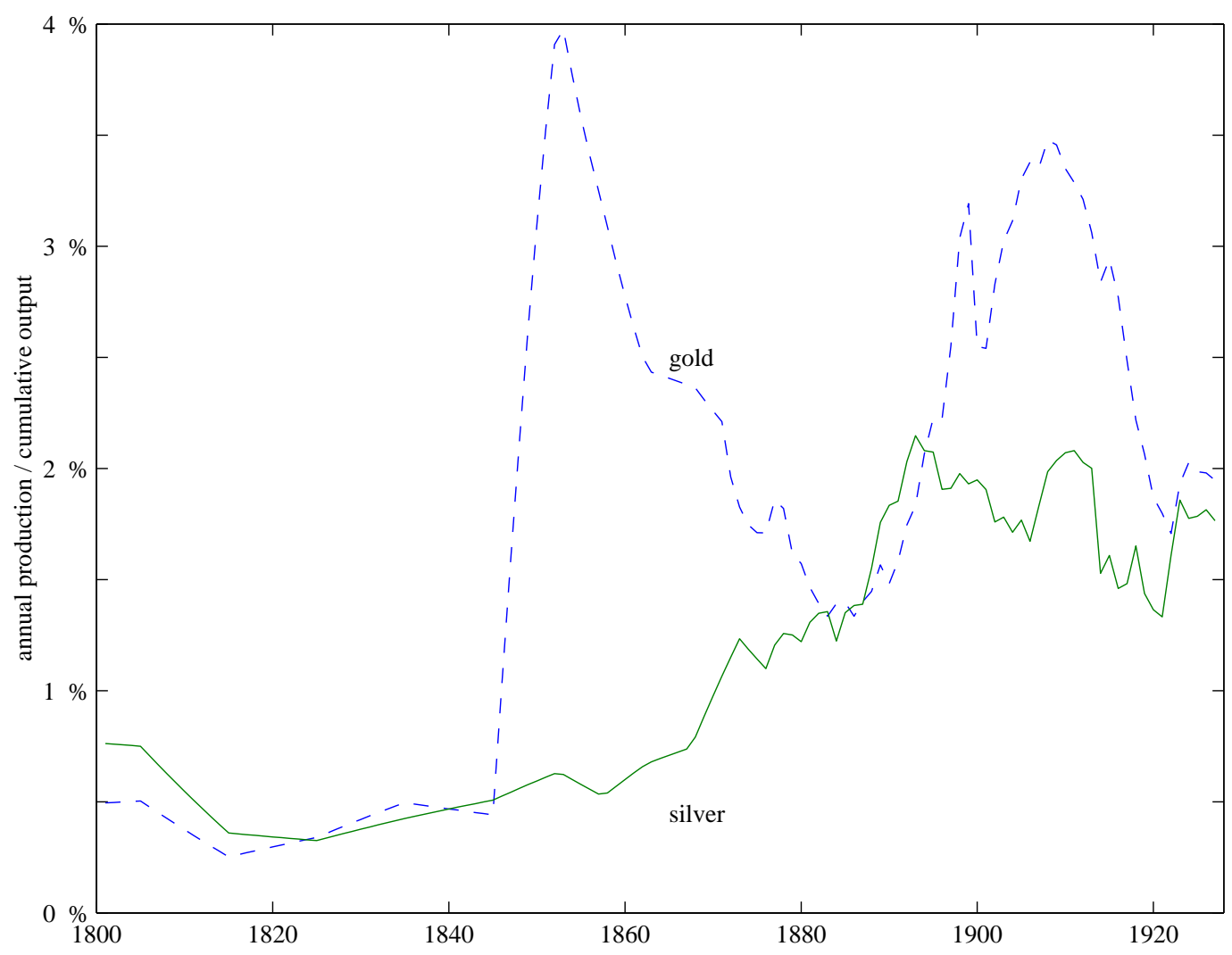

Figure 2: Annual world production of gold and silver, as a percentage of existing stock. See Appendix 2 for sources.

\section{The Literature}

Bimetallism has the been the subject of considerable debate in the 19th century (Darwin 1898, Fisher 1911, Laughlin 1896, Shaw 1894, Willis 1901). At the turn of the century, any textbook dealing with money touched on the subject. With the simultaneous abandonment of bimetallism by France and the United States in 1873, and the end of subsequent political agitation after the defeat of William Jennings Bryan's bid for the U.S. presidency, the debate was seen as academic, some writers viewing its disappearance as resolution of the debate against it. More recently, the debate has 


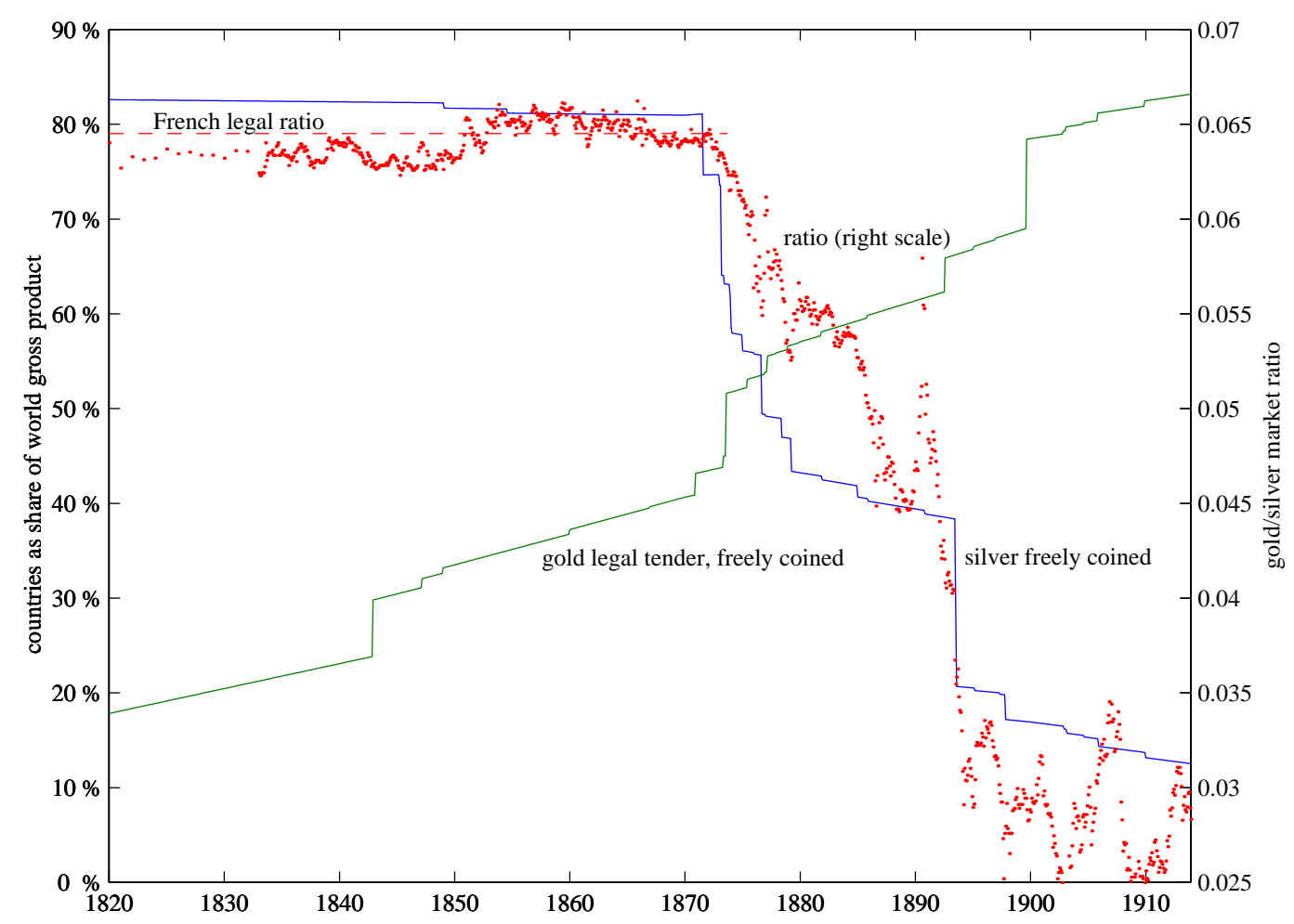

Figure 3: Countries with free coinage of silver, and countries with free coinage of and legal tender laws for gold, as share of world output (monthly, 1820-1913). See Appendix 2 for sources.

been revived (Friedman 1990a, 1990b; Redish 1990, 1995; Oppers 1995, 1996; Dowd 1996; Flandreau 1996, 1997).

In the debates about bimetallism versus either gold or silver monometallism, it is necessary to distinguish whether the arguments for bimetallism concern a particular country or whether they concern the world as a whole, or at least a large group of countries. To borrow Laughlin's terminology, there are advocates of national bimetallism: a country should adopt bimetallism on its own regardless of what other countries do, and advocates of international bimetallism: the major trading countries should agree on a common bimetallic standard. It is likely that the advocates of national bimetallism would have been in favor or international bimetallism, in principle, although they might have objected to the particular ratio agreed upon. However, it was not necessarily the case the advocates of international bimetallism would have been in fa- 
vor or national bimetallism. In discussing the debate, we will implicitly assume that advocacy of bimetallism is advocacy of international bimetallism rather than national bimetallism.

\section{Viability}

The question of the viability of bimetallism can be posed in two ways. The first is whether or not it is possible for gold and silver to be in concurrent circulation for long periods of time without a change in the mint (legal) ratio. The second is whether it is inevitable in the long run that the majority of countries would adopt a gold monometallic standard.

With regard to the issue of long-term concurrent circulation, the conventional monometallic view against is well stated by Friedman (1990a, 87): "bimetallism is an unstable and unsatisfactory monetary standard involving frequent shifts between alternative monometallic standards." The supply and demand for gold and silver are continually subjected to shocks which will cause the market ratio of the metals to differ from the legal ratio. This will cause bimetallic standards to exhibit a knifeedge property caused by the operation of Gresham's Law, with the type of metal in circulation switching between gold and silver as the market ratio is either above or below the mint ratio.

Some proponents of bimetallism argue that the setting of a legal ratio will stabilize the market price at the legal ratio. Given this stability, agents will be indifferent as to which metal they use as money, so both will be in circulation.

More sophisticated defenders of bimetallism like Irving Fisher (1911) do not argue that the market ratio must equal the mint ratio under bimetallism. They acknowledge that shocks to supply and demand can cause the market ratio to fluctuate and that deviations from the market ratio can cause a metal to go out of circulation. They actually acknowledged that maintaining concurrent circulation of both metals would require adjustments in the legal ratio. However, their argument is that such adjustments would only be required infrequently for two reasons. First, there are costs, 
such as shipping, to arbitraging between the two metals. Such costs mean that small differences between market and mint ratios will not lead to one metal disappearing from circulation. Second, the size of shocks to the demand and supply of the two metals would be small enough relative to each other and hence "we may be tolerably confident that, if initially successful with the film near the middle position [the stocks of gold and silver coins close to equal], international bimetallism would continue successful for many generations. The initial success depends, as has been seen, upon the ratio enacted" (p. 125). Fisher does concede that "two nations cannot both maintain bimetallism at two different ratio unless the difference is less than the cost of shipment. One of the nations would lose the metal which is undervalued and find itself on a monometallic basis" (p. 124) This is why international bimetallism is important in his view.

The empirical evidence cited by both sides of the debate seems to be France between 1803 and 1873. The proponents of monometallism argue that the market ratio deviated from the mint ratio over this period, showing that bimetallism does not stabilize the market ratio. Further, they argue that when the market ratio fell below the mint ratio in the late 1840s, France switched from being on a silver monometallic country to being a gold monometallic one.

The proponents of bimetallism argue that the market ratio actually was relatively stable around the mint ratio during this period. Calculations by Flandreau (1996, 1997) show that, in nineteenth-century France, the market ratio remained with in the arbitrage bounds (gold-silver points) at which arbitrage would have been possible, and that both gold and silver were in fact in concurrent circulation. However, even Fisher (1911, 135-6) admits that "in 1850 bimetallism had almost broken down in France and would have been succeeded by silver monometallism had not the increased production of gold reversed the flow."

With regard to inevitability, the argument of the gold monometallists, at least as put forward by Laughlin and Shaw, seems to be the gold standard was inevitable because gold is the preferred medium of exchange by wealthy and commercial advanced countries. Thus, as nations become wealthier and international trade became more important, the adoption of a gold standard was inevitable. Redish has further 
argued that the adoption of the gold standard was facilitated by the development of coinage technology, the steam press, which made token coinage much more difficult to counterfeit.

Defenders of bimetallism, in particular Fisher, Friedman, and Flandreau, regard the adoption of the gold standard as being an historical accident. Moreover, Fisher (1911, 323-4) explicitly acknowledges that it is very probably an irreversible one: "it is not too much to say that we have hit upon the gold standard by accident. . . . Now that we have adopted a gold standard, it is almost as difficult to substitute another as it would be to establish the Russian railway gauge or the duodecimal system of numeration."

Welfare

The major welfare issues concern price stability and international trade. The proponents of bimetallism argue that it would provide greater price stability. The bimetallic argument is given by Fisher (1911, 325) as follows:

As we have seen, by connecting the currencies of both gold and silver countries, bimetallism, as long as it continues in working order, has the effect of spreading any variation of one particular metal over the combined area of gold, silver, and bimetallic countries. If variations occur simultaneously in both metals, they may be in opposite directions, and neutralize each other more or less completely; while, even if they happened to be in the same direction, the combined effect on the whole world united under bimetallism would be not greater than on the two halves of the of the world under silver and gold monometallism respectively. Even if bimetallism did not enlarge the monetary area, it might reduce monetary fluctuations.

Walras stated the same argument a bit more succinctly: "In short, bimetallism is as much at the mercy of chance as monometallism so far as stability of the value of the monetary standard is concerned; on bimetallism has a few more chances in its favor" 
(Walras 1977, 359).

The counter argument by some monometallists is that this price stability (called "compensatory action" by Laughlin) occurs only if one metal drives the other out of circulation. However, such action requires the (deadweight) loss involved in recoining the entire stock of money in a country. Giffen $(1892,18)$ takes a slightly different approach. He argues that the amount of price fluctuation caused by shocks to the demand and supply of precious metals is quite small relative to those "constantly being produced by changes in credit alone." Further, he seems to have some notion of monetary neutrality in mind, at least for moderate changes in money, so that he concludes that "moderate changes in the quantity of money in use, unless they are suddenly made, are not material."

Proponents on both sides of the debate seem to agree that it would be best if all major commercial countries were to agree on a common monetary standard since this would eliminate the exchange rate uncertainty from international trade. Proponents of bimetallism argued for an addition benefit of their standard with regard to trade with countries like Japan and China (and perhaps India), which were likely to remain on a silver standard for quite some time. Giffen's response to this argument is that foreign trade is only a small part of the trade of the country, so that decision of which standard is best should not be made on this basis. 


\section{A Model of Bimetallism}

Time is discrete and without end. There are three goods: a consumption good $c_{t}$, and stocks of gold and silver bullion. Consumption is non-storable, while gold and silver are durable and do not depreciate. There is an exogenous endowment $X_{t}=\left(\xi_{t}, Q_{1, t}, Q_{2, t}\right)$ of which $\xi_{t}$ can be turned into consumption goods subject to the constraint

$$
c_{t} \leq \xi_{t}
$$

and $Q_{i, t}(i=1,2)$ represent the total existing stocks of gold and silver bullion respectively, measured in ounces. The vector $X_{t}$ is stochastic, and constitutes the only source of uncertainty. Its probability distribution is known to agents.

Bullion can be in two possible forms: jewelry (by which we mean metal in any use other than monetary) and coins. Consumers care about consumption and about the stock of jewelry $d_{1, t}$ and $d_{2, t}$ (measured in ounces) that they own. Accordingly, preferences are

$$
E_{0} \sum_{t=0}^{\infty} \beta^{t}\left[u\left(c_{t}\right)+v\left(d_{1, t+1}, d_{2, t+1}\right)\right]
$$

where $E_{t}$ denotes the expectations operator conditional on beginning of period $t$ information (namely, the history $X_{0}, \ldots, X_{t}$ ). The function $u$ is concave, twice differentiable with $u^{\prime}(0)=+\infty$, the function $v$ is concave, twice differentiable.

Coins are needed by the household to meet a cash-in-advance constraint on its purchases, which are made in a manner to be described shortly. A coin is defined by a number $b_{i}(i=1,2)$, which is in ounces of gold (silver) per coin. Coins are produced by a competitive firm, which converts jewelry bought from the household into coins (paying a tax at a rate $\sigma_{i}$ on all new coins). The firm can also convert coins into jewelry. Both operations are costless but can only be carried out by the firm. Both types of coins are perfect substitutes in the cash-in-advance constraint at a ratio of substitution $e_{t}$. Coins of metal 1 are by convention called dollars $(\$)$, coins of metal 2 are valued at $\$ e_{t}$ each. We allow for $e_{t}$ to be endogenous, but will also consider equilibria where it is a constant. 
At the beginning of a period, the realization of $X_{t}$ becomes known. At that point, the household owns the endowment, the stocks of jewelry, and the stocks of coins; the change in the stock of bullion since the end of the previous period accrues directly to the stock of jewelry. The household sells its endowment to the firm in exchange for a claim to the firm's profit. The shopping session begins: with its coin balances, the household buys from the firm consumption at the competitively determined price $p_{t}$ (in $\$ /$ good), and $h_{i, t}$ ounces of new jewelry at the price $q_{i, t}$ (in $\$ /$ oz). ${ }^{3}$ The firm sells the endowment and the new jewelry to the household in exchange for coins. It then mints $n_{i, t}$ coins and melts $\mu_{i, t}$ coins, and finally turns over all profits (in the form of coins) to the household at the end of the period.

The firm's profit, in dollars, is

$$
\begin{aligned}
\Pi_{t}=p_{t} c_{t}+ & \left(n_{1, t}-\sigma_{1} n_{1, t}\right)-\mu_{1, t}+q_{1, t} h_{1, t} \\
& +e_{t}\left(n_{2, t}-\sigma_{2} n_{2, t}\right)-e_{t} \mu_{2, t}+q_{2, t} h_{2, t}
\end{aligned}
$$

The firm maximizes (3) by choosing each period $c_{t}, \mu_{i, t}, n_{i, t}, h_{i, t}$ subject to the constraints (1) and

$$
\begin{aligned}
& 0 \leq n_{i, t}, \quad 0 \leq \mu_{i, t} \leq m_{i, t} \\
& h_{i, t}=b_{i}\left(\mu_{i, t}-n_{i, t}\right) .
\end{aligned}
$$

As a result of the firm's choices, the new stocks of coins are given by:

$$
m_{i, t+1}=m_{i, t}+n_{i, t}-\mu_{i, t}
$$

In order to encompass various possible monetary arrangements, some particular variants will be allowed. In particular, the sale of jewelry in one particular metal may be shut down. This corresponds to an additional constraint on the household: $h_{i, t} \geq 0$ for all $t$. This captures cases where the mint was closed to one metal. To capture the case of a single standard with a purely token secondary coinage, we may also rule

${ }^{3}$ Purchases of consumption and jewelry are simultaneous, so the purchase of jewelry requires additional coin balances; conversely, the sale of jewelry by the household can be credited against consumption purchases). 
out melting down one type of coin (taking it to be intrinsically useless), in which case $h_{i, t}=0$.

The government collects seigniorage and transfers it as a lump-sum $T_{t}$ to the household at the end of the period:

$$
T_{t}=\sigma_{1} n_{1, t}+\sigma_{2} n_{2, t}
$$

The household maximizes (2) by choosing sequences for $d_{i, t+1}, c_{t}, h_{i, t}, m_{i, t+1}$ subject to the laws of motion

$$
d_{i, t+1}=d_{i, t}+h_{i, t}+\left(Q_{i, t+1}-Q_{i, t}\right)
$$

the cash-in-advance constraint

$$
p_{t} c_{t}+q_{1, t} h_{1, t}+q_{2, t} h_{2, t} \leq m_{1, t}+e_{t} m_{2, t}
$$

and the budget constraint

$$
m_{1, t+1}+e_{t} m_{2, t+1} \leq \Pi_{t}+\left(m_{1, t}+e_{t} m_{2, t}-p_{t} c_{t}-q_{1, t} h_{1, t}-q_{2, t} h_{2, t}\right)+T_{t}
$$

(taking $\Pi_{t}$ as given) as well as the constraints

$$
\begin{aligned}
& c_{t} \geq 0 \quad m_{i, t+1} \geq 0 \\
& h_{i, t} \geq-d_{i, t}-\left(Q_{i, t+1}-Q_{i, t}\right),
\end{aligned}
$$

$d_{i, 0}$ and $m_{i, 0}$ given.

Market clearing requires that the household and the firm choose the same $c_{t}$ and $h_{i, t}$, and that the household choose $m_{i, t+1}$ such that (5) holds.

\section{Equilibrium}

It is now possible to define various monetary systems as sub-classes of equilibria in this model. In general, an equilibrium is defined as follows: 
Definition 1. An equilibrium is a collection $\left\{m_{i, t+1}\right\},\left\{\mu_{i, t}\right\},\left\{n_{i, t}\right\}\left\{d_{i, t+1}\right\},\left\{h_{i, t}\right\}$ $\left\{p_{t}\right\},\left\{q_{i, t}\right\},\left\{e_{t}\right\}$, such that: (a) the firm maximizes (3) subject to (1), (4); (b) the household maximizes (2) subject to (6), (7), (8), (9); (c) $c_{t}=\xi_{t}$ and (5) holds.

Bimetallism can be defined as existing in certain equilibria, those for which:

(C1) $m_{1, t+1}>0, m_{2, t+1}>0$ for all $t$ (both metals circulate as coinage)

(C2) $e_{t}=e_{t+1}$ for all $t$ (legal tender laws apply).

Strict monometallism can be defined as an equilibrium satisfying $m_{j, t}=0$ for all $t$. Monometallism with trade money can be defined as an equilibrium satisfying (C1) only. The other form of monometallism, where free minting of only one metal is permitted, can be defined as an equilibrium where the household faces the additional

constraint: $h_{j, t} \geq 0$ for some $j$. If the constraint is $h_{j, t} \geq 0$ and $m_{j, t+1}>0$, we have a limping standard.

First-order conditions

The firm's first-order conditions are (1), (4) and:

$$
\begin{aligned}
& q_{1, t} \geq \frac{1-\sigma_{1}}{b_{1}}, \quad n_{1, t} \geq 0 ; \quad n_{1, t}=0 \text { if } q_{1, t}>\frac{1-\sigma_{1}}{b_{1}} \\
& \mu_{1, t} \geq 0 ; \quad \mu_{1, t}=0 \text { if } q_{1, t}<\frac{1}{b_{1}} \\
& \mu_{1, t} \leq m_{1, t} ; \quad \mu_{1, t}=m_{1, t} \text { if } q_{1, t}>\frac{1}{b_{1}} \\
& q_{2, t} \geq e_{t} \frac{1-\sigma_{2}}{b_{2}}, \quad n_{2, t} \geq 0 ; \quad n_{2, t}=0 \text { if } q_{2, t}>e_{t} \frac{1-\sigma_{2}}{b_{2}} \\
& \mu_{2, t} \geq 0 ; \quad \mu_{2, t}=0 \text { if } q_{2, t}<\frac{e_{t}}{b_{2}} \\
& \mu_{2, t} \leq m_{2, t} ; \quad \mu_{2, t}=m_{2, t} \text { if } q_{2, t}>\frac{e_{t}}{b_{2}}
\end{aligned}
$$

These first order conditions are in the nature of no-arbitrage constraints, as in Sargent and Smith (1997). They place lower bounds on the prices of jewelry $q_{i, t}$, bounds at which new coins are minted (minting points). They also define melting points for 
$q_{i, t}$, above which all coins of type $i$ are melted. Also, minting occurs only at the minting point, and melting only at the melting point or above. The quantity $1 / b_{1}\left(\right.$ resp. $\left.e_{t} / b_{2}\right)$ is the mint equivalent of coin 1 (resp. coin 2), and $\left(1-\sigma_{1}\right) / b_{2}\left(\operatorname{resp} .\left(1-\sigma_{2}\right) e_{t} / b_{2}\right)$ its mint price.

The household's first-order conditions are (6), (7), (8), (9) and:

$$
\begin{gathered}
v_{i}\left(d_{t+1}\right)=\frac{q_{i, t}}{p_{t}} u^{\prime}\left(c_{t}\right)-\beta E_{t}\left[\frac{q_{i, t+1}}{p_{t+1}} u^{\prime}\left(c_{t+1}\right)\right] \\
E_{t}\left[\left(\frac{e_{t+1}}{e_{t}}-1\right) \frac{u^{\prime}\left(c_{t+1}\right)}{p_{t+1}}\right]\left\{\begin{array}{l}
\leq 0 \quad \text { if } m_{1, t+1}>0, \\
\geq 0 \quad \text { if } m_{2, t+1}>0,
\end{array}\right. \\
\beta \max \left\{E_{t}\left[\frac{u^{\prime}\left(c_{t+1}\right)}{p_{t+1}}\right], E_{t}\left[\frac{e_{t+1}}{e_{t}} \frac{u^{\prime}\left(c_{t+1}\right)}{p_{t+1}}\right]\right\} \leq \frac{u^{\prime}\left(c_{t}\right)}{p_{t}},
\end{gathered}
$$

with (11d) holding at equality when (7) does not bind, and use of the notation $v_{i}\left(d_{t+1}\right)=\partial v / \partial d_{i}\left(d_{1, t+1}, d_{2, t+1}\right)$.

Equation (11a) is an asset pricing equation for jewelry, (11b) and (11c) require that one currency not be dominated in rate of return by the other if it is held, and (11d) places a lower bound of 1 on the gross nominal rate of interest.

\section{Absence of Seigniorage: $\sigma_{i}=0$}

We begin with the case where seigniorage is 0 . This is not a bad approximation, as argued above. It allows us to examine the broad dynamics of bimetallism in response to supply or demand shocks to the metals. We first analyze the steady state under certainty, and prove that there exists a continuum of bimetallic equilibria indexed by the ratio $e$. We also find that, for the CES class of preferences, the equilibria can be ranked and monometallism always dominates bimetallism. Then we analyze the conditions under which bimetallism gives way to monometallism. Finally, we analyze the dynamics under uncertainty; for the logarithmic class of preferences we prove existence of equilibrium and numerically compute equilibria. 


\section{Steady State Analysis}

Shut down the uncertainty for now: $X_{t}=X=\left(\xi, Q_{1}, Q_{2}\right)$ for all $t$. Can we choose $d_{1}, d_{2}$ in such a manner as to support a steady state competitive equilibrium?

In a steady state where both coins are held, $(11 b)$ and (11c) implies that $e_{t}$ is a constant. Furthermore, (11a) becomes

$$
\frac{v_{i}(d)}{u^{\prime}(\xi)}=\frac{q_{i}}{p}(1-\beta)
$$

and (10) with $\sigma_{i}=0$ imply $q_{1}=1 / b_{1}$ and $q_{2}=e / b_{2}$.

We now have the following equations:

$$
\begin{aligned}
b_{1} m_{1} & =Q_{1}-d_{1} \\
b_{2} m_{2} & =Q_{2}-d_{2} \\
p & =(1-\beta) \frac{u^{\prime}(\xi)}{b_{1} v_{1}(d)} \\
p & =e(1-\beta) \frac{u^{\prime}(\xi)}{b_{2} v_{2}(d)} \\
p \xi & =m_{1}+e m_{2}
\end{aligned}
$$

These five equations in the six unknowns $e, m_{1}, m_{2}, p, d_{1}, d_{2}$ are exactly those identified by Walras in his Lesson 31 (1977, 337-8), leading him to conclude that "the legislator can intervene, and either determine one of the six unknowns arbitrarily or introduce a sixth equation in one way or another. . . If the legislator exerts his arbitrary power on quantity, the value will be automatically determined in the market. If he exerts it on value, then the quantity will be automatically determined by the mechanism of free competition."

The system (12) can be reduced ${ }^{4}$ to:

$$
\left(Q_{1}-d_{1}\right) v_{1}(d)+\left(Q_{2}-d_{2}\right) v_{2}(d)=(1-\beta) u^{\prime}(\xi) \xi .
$$

${ }^{4}$ Rewrite $(12 e)$ as $b_{1} p \xi=b_{1} m_{1}+\left(e b_{1} / b_{2}\right) b_{2} m_{2}$, then use (12a) and (12b) to replace $b_{i} m_{i},(12 c)$ to replace $b_{1} p$ and $(12 d)$ to replace $e b_{1} / b_{2}$. 
Equation (13) is the quantity theory equation stated in terms of the weights of gold and silver coin, each valued at its marginal utility as jewelry. Under the concavity assumption on the function $v,(13)$ defines a monotone decreasing curve in the $\left(d_{1}, d_{2}\right)$ plane. If, moreover,

$$
Q_{i} \lim _{d_{i} \rightarrow 0} v_{i}\left(d_{i}, Q_{3-i}\right)>(1-\beta) u^{\prime}(\xi) \xi
$$

for $i=1,2$, then the curve intersects both lines $d_{i}=Q_{i}$.

Along that curve, the market ratio $q_{1} / q_{2}=v_{1}(d) / v_{2}(d)$ varies. The legal ratio $b_{2} / e b_{1}$ also varies, since it is pegged to the market ratio by the equilibrium conditions $(12 c)$ and $(12 d)$. The range of legal ratios that are compatible with equilibrium, that is, for which there exists a pair $\left(d_{1}, d_{2}\right)$ on the curve, is an interval. Figure 4 shows the curve for the case:

$$
v\left(d_{1}, d_{2}\right)=\alpha_{1} \log \left(d_{1}\right)+\alpha_{2} \log \left(d_{2}\right)
$$

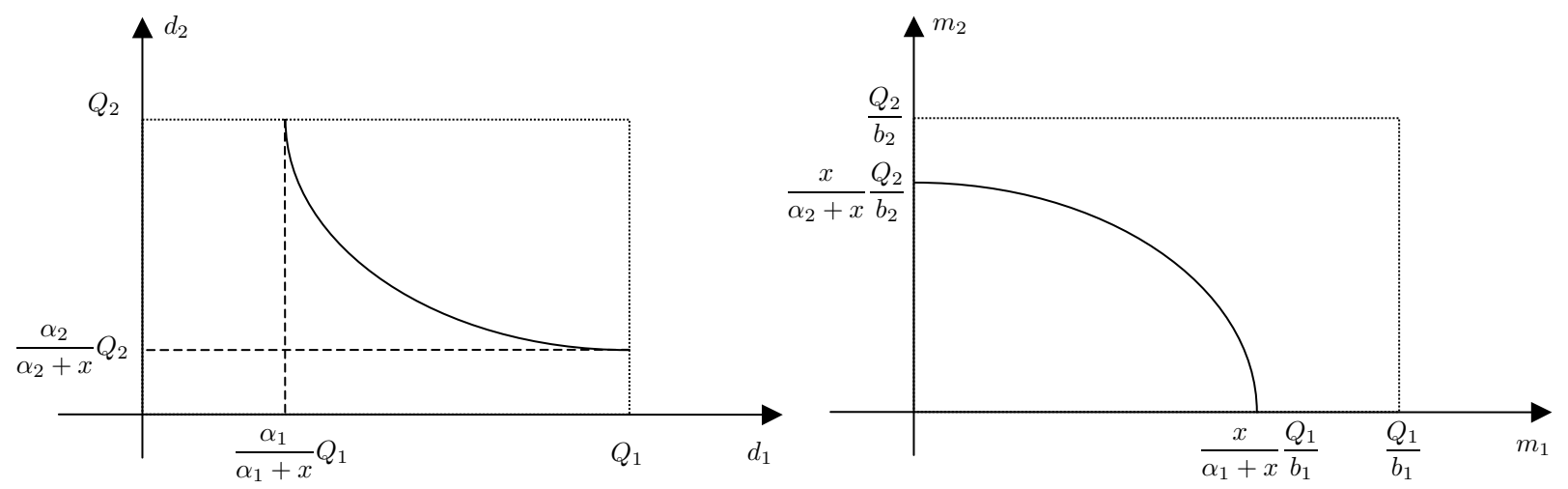

Figure 4: Set of steady state equilibria, represented in the $\left(d_{1}, d_{2}\right)$ plane (left panel) and in the $\left(m_{1}, m_{2}\right)$ plane.

All the points on the interior of that curve correspond to bimetallic steady states, with concurrent circulation of both metals and a constant exchange rate. The points where the curve intersects the lines $Q_{i}=d_{i}$ correspond to monometallism, and to limits $\underline{e}, \bar{e}$ on ratios compatible with bimetallism. In the log preference case, the limits on the mint ratio are

$$
\left(\frac{\alpha_{1}}{\alpha_{2}} \frac{Q_{2}}{Q_{1}}\right) \frac{\alpha_{2} / x}{1+\alpha_{2} / x} \leq \frac{b_{2}}{e b_{1}} \leq\left(\frac{\alpha_{1}}{\alpha_{2}} \frac{Q_{2}}{Q_{1}}\right) \frac{1+\alpha_{1} / x}{\alpha_{1} / x}
$$


where $x=(1-\beta) u^{\prime}(\xi) \xi$. The lower bound corresponds to the silver standard.

We summarize these results.

Proposition 1. There exists a continuum of steady-state equilibria with concurrent circulation of both metals as money. These equilibria are indexed by the gold/silver ratio $e$ in a range $(\underline{e}, \bar{e})$, with $0<\underline{e}$ and $\bar{e}<+\infty$ and in each equilibrium the mint ratio e equals the market ratio. For parameter values satisfying (14), the equilibria for $e$ such that $0<e \leq \underline{e}$ (resp. $\bar{e} \leq e<+\infty$ ) are silver (resp. gold) monometallic.

Each equilibrium corresponds to a different allocation $\left(d_{1}, d_{2}\right)$. What are the welfare properties of the set of equilibria? Holding $\xi$ fixed, we can pose the problem

$$
\max _{d_{1}, d_{2}} v\left(d_{1}, d_{2}\right)
$$

subject to (13). For two classes of utility functions, we have the following result:

Proposition 2. If preferences over jewelry are of the form $v\left(d_{1}, d_{2}\right)=a_{1} d_{1}^{\gamma_{1}}+a_{2} d_{2}^{\gamma_{2}}$ for $0<\gamma_{i}<1$, or $\left(a_{1} d_{1}^{\rho}+a_{1} d_{2}^{\rho}\right)^{1 / \rho}$ for $\rho<1, a_{i}>0$ then, among steady states:

1) welfare is minimized at $d_{1} / d_{2}=Q_{1} / Q_{2}$,

2) welfare is maximized by either $d_{1}=0$ or $d_{2}=0$.

For those preferences, the first-order condition for $(\mathrm{W})$ identifies the unique interior point on the curve defined by (13) that also satisfies $d_{1} / d_{2}=\left(Q_{1}-d_{1}\right) /\left(Q_{2}-d_{2}\right)$. At that point, $v_{1}(d) / v_{2}(d)=v_{1}(Q) / v_{2}(Q)$ which is the ratio which would prevail in the absence of monetary uses of the metals, also called the "natural ratio" (Darwin 1890, 20). That point turns out to be a minimizer, not a maximizer. The constrained optimum is achieved at the bounds, either at $d_{1}=0$ or $d_{2}=0$; in other words, with monometallism. ${ }^{5}$

5 The proof relies on algebra, using the properties of the utility function. In the CES case, the main property is that the cross derivative is $v_{12}=-\left(d_{1} / d_{2}\right) v_{11}=-\left(d_{2} / d_{1}\right) v_{22}$; this, in turn, allows to express cross third derivatives in terms of $v_{111}$ and $v_{222}$. When the bordered Hessian of the Lagrangian is computed, exploiting properties of the solution to the first-order condition, it is found to be always negative. 


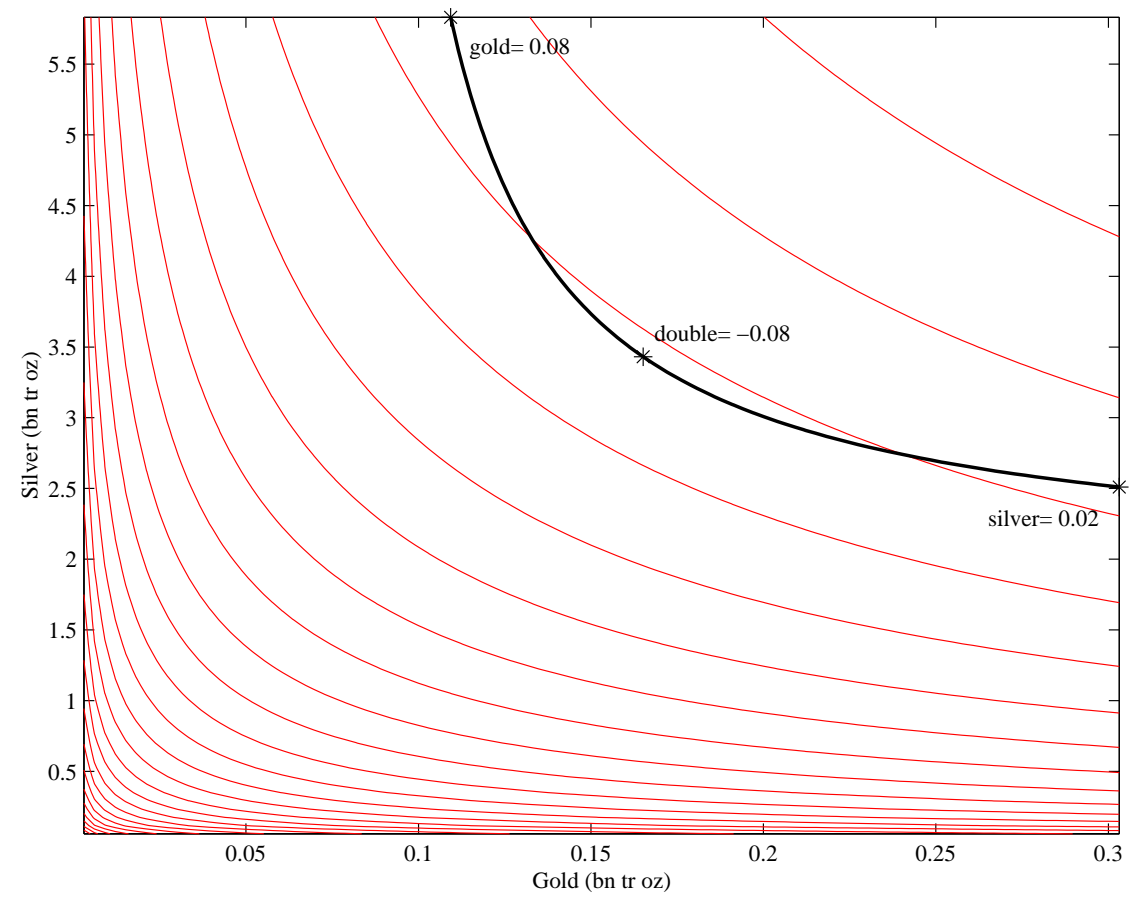

Figure 5: Set of steady state equilibria, log preferences calibrated to 1873 data (see Appendix 2). The value of utility is indicated next to the location of the gold, silver and double standard (15.5 legal ratio). The lightly shaded lines are indifference curves.

There is a cost to using a metal as money, which is that it cannot be a source of utility. With constant elasticity of substitution between the two, one metal is always better employed instead of the other as money. The price stability properties of bimetallism must be assessed against this welfare cost.

How big is that cost? For our calibration to 1873 figures (described in the Appendix 2), moving from bimetallism to a gold standard corresponds to a permanent increase in the gold stock available for non-monetary purposes from $165 \mathrm{~m}$ to $222 \mathrm{~m}$ troy oz. The value of the net increase is $\$ 1.2 \mathrm{bn}$ at 1873 prices, which amounts to $20 \%$ of U.S. GDP or about $1.7 \%$ of world output. ${ }^{6}$ The welfare loss is not insignificant.

\section{Dynamics under Certainty}

6 U.S. GDP in current dollars from Kausel (1985, table 2). The U.S. represented about $8.7 \%$ of world output at the time and world population was about 1.265bn (Maddison 1995, 182, 226, 227). The U.S. dollar was set at $\$ 21.333$ per troy oz in 1837 . 
The analysis so far assumes constant stocks of gold and silver. If the two stocks of money grow at the same rate, the analysis is easy to modify, and the previous results hold around the trend, rather than the constant values of the stocks. If the stock of one metal grows at a rate higher than the other other, the effect is to shift the curve in Figure 4 to the right. Suppose the faster growing metal is metal 1. Since equilibria for a fixed $e$ lie along a positively sloped ray from the origin, shifts imply that increases in metal 1 will lead to increased amounts of jewelry of both metals. Thus, coins of metal 2 are being melted, and it is easy to show that coins of metal 1 are being minted to take their place in transactions. Eventually this process will lead to all of metal 2 being used as jewelry. (The ray must eventually intersect the $Q_{2}$ upper bound to the left of the curve.) In other words, when metal 1 grows faster than metal 2 , $\underline{e}$ continually increases, so that eventually it must become larger than $e$. Thus, unless the legal ratio is changed, the economy will ultimately end up having the faster growing metal as its de facto monetary standard. Figure 1 shows that the growth rate of gold stocks increased markedly above that of silver stocks in 1850. Were that change to persist long enough, the gold standard ultimately had to prevail, unless bimetallic countries were willing to countenance a lower gold/silver ratio, and implement the change in a coordinated manner.

But was that change in relative growth rates of silver and gold stocks the cause for the collapse of bimetallism in 1873? Figure 6 plots the upper and lower bounds defined in (16) under log preferences calibrated to 1873 figures (see Appendix 2). We see the market ratio reaching the upper bound (corresponding theoretically to the gold standard equilibrium) by the late 1890s; and indeed, at that time almost all countries had abandoned bimetallism, as shown in Figure 3. However, the French legal ratio of 15.5:1 lies within the bounds well into the twentieth century, indicating that no change in the legal ratio would have been required for the world to have concurrent circulation of gold and silver coins for a long time (quote Fisher making exactly that point). The figure also confirms Fisher's analysis that even though the legal ratio might have to be changed from time to time to keep both coins in circulation, these changes would be relatively infrequent if the ratio was chosen close to the middle of the band.

\section{Dynamics under Uncertainty}




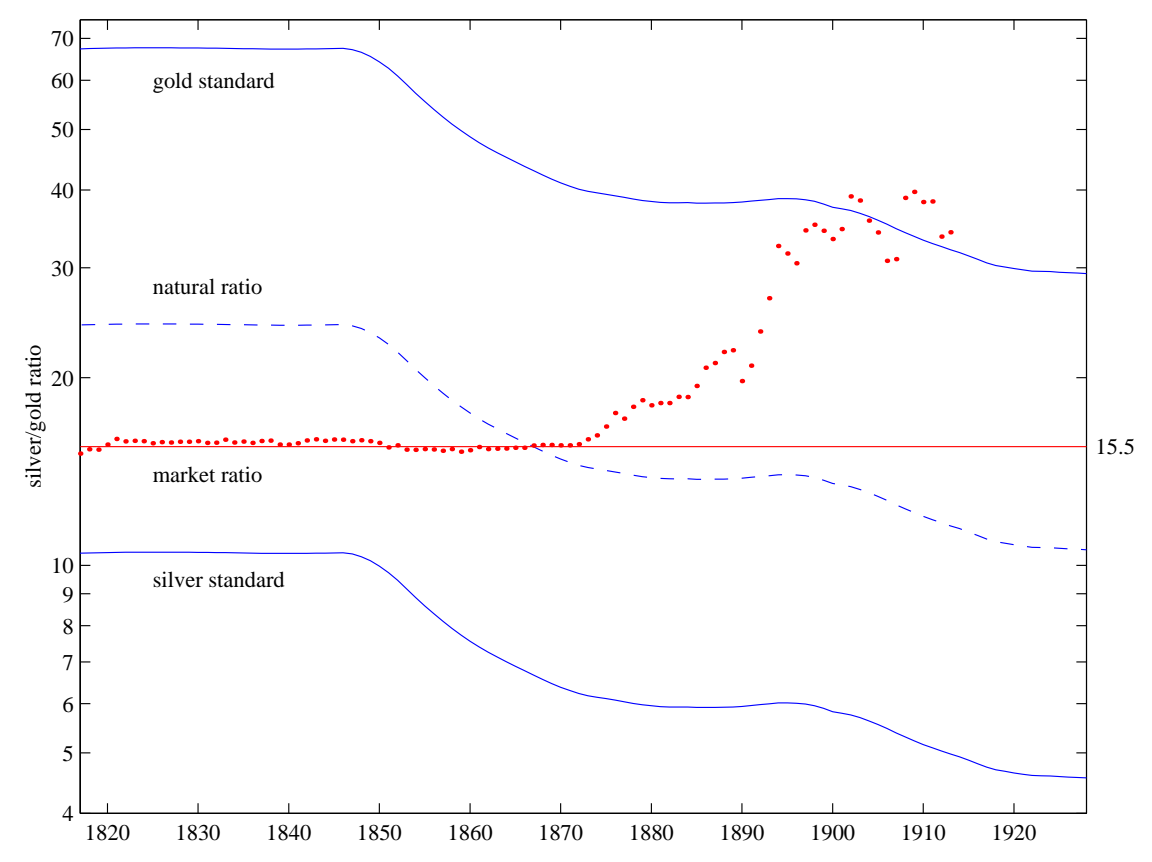

Figure 6: Upper and lower bound on the legal ratio, 1816-1913.

We now consider the case in which the stocks of the two metals are subject to stochastic shocks. For the specific case of log preferences we prove existence of a bimetallic equilibrium with concurrent circulation of both metals and we present simulation results on welfare and price stability. We also consider the case of trade money.

Condition $(C 1)$ requires concurrent circulation of both coins. When $(C 1)$ is satisfied but $e_{t}$ is free to vary, we call the resulting equilibrium a trade-money equilibrium. When $(C 2)$ is imposed as well, we have a bimetallic equilibrium. We first impose $(C 1)$, to derive conditions that are common to a trade money and a bimetallic equilibrium; later, we impose $(C 2)$.

Condition $(C 1)$, combined with the firm's first-order conditions (10), implies that $q_{1, t}=1 / b_{1}$ and $q_{2, t}=e_{t} / b_{2}$. In turn, this transforms $(11 a)$ into:

$$
b_{1} v_{1}\left(d_{t+1}\right)=\frac{u^{\prime}\left(c_{t}\right)}{p_{t}}-\beta E_{t}\left[\frac{u^{\prime}\left(c_{t+1}\right)}{p_{t+1}}\right]
$$




$$
\frac{b_{2}}{e_{t}} v_{2}\left(d_{t+1}\right)=\frac{u^{\prime}\left(c_{t}\right)}{p_{t}}-\beta E_{t}\left[\frac{e_{t+1}}{e_{t}} \frac{u^{\prime}\left(c_{t+1}\right)}{p_{t+1}}\right]
$$

which implies that (11d) always holds.

By $(11 b)$ and $(11 c),(C 1)$ also implies that the rates of returns on the two monies be equal, in the sense that:

$$
E_{t}\left[\frac{u^{\prime}\left(c_{t+1}\right)}{p_{t+1}}\right]=E_{t}\left[\frac{e_{t+1}}{e_{t}} \frac{u^{\prime}\left(c_{t+1}\right)}{p_{t+1}}\right] .
$$

Equations (17) and (18) also imply that the market ratio, or relative price of gold and silver jewelry, equals the relative price of gold and silver coin:

$$
\frac{v_{1}\left(d_{t+1}\right)}{v_{2}\left(d_{t+1}\right)}=\frac{b_{2}}{e_{t} b_{1}}
$$

Equations (4b), (5), (6) and (7) imply

$$
p_{t} c_{t}=\frac{1}{b_{1}}\left(Q_{1, t+1}-d_{1, t+1}\right)+\frac{e_{t}}{b_{2}}\left(Q_{2, t+1}-d_{2, t+1}\right) .
$$

In equilibrium, $c_{t}=\xi_{t}$. The dynamical system consists of $e_{t-1}, d_{1, t}, d_{2, t}, p_{t}$ and the equations $(17 a),(18),(20)$ and $(17 b)$ or (19). Using (20) to replace $p_{t}$ and (19) to replace $e_{t}$, we can reduce the system to a difference equation in $d_{t}$ only.

If we add condition $(C 2)$ and make $e_{t}$ a constant, (18) is always satisfied. Equation (19) allows us to express $d_{2, t+1}$ as a function of $d_{1, t+1}$. Then the dynamical system becomes $d_{1, t+1}$ and $p_{t}$ with equations (20) and (17a).

Existence of Equilibrium (Log Case)

With the preferences (15), (19) becomes

$$
d_{2, t+1}=\frac{\alpha_{2}}{\alpha_{1}} \frac{b_{2}}{e b_{1}} d_{1, t+1}
$$

and (20) becomes

$$
p_{t}=\frac{1}{\xi}\left(Q_{1, t+1} / b_{1}+e Q_{2, t+1} / b_{2}-a d_{1, t+1}\right)
$$


with and $a=\left(1+\alpha_{2} / \alpha_{1}\right) / b_{1}$. Let $z_{t}=Q_{1, t+1} / b_{1}+e Q_{2, t+1} / b_{2}$. Equation $(17 a)$ is now

$$
\frac{1}{z_{t}-a d_{1, t+1}}-\frac{c}{d_{1, t+1}}=\beta E_{t}\left[\frac{1}{z_{t+1}-a d_{1, t+2}}\right]
$$

with $c=b_{1} \alpha_{1} /\left[\xi u^{\prime}(\xi)\right]$. We want to solve for a policy function $d_{1, t+1}=d\left(z_{t}\right)$ satisfying (23).

The proof of existence is given in the Appendix. It is a constructive proof: we transform (23) into a fixed point equation for a monotone operator $T$ defined on a suitable subset $F$ of a functional space $C(Z)$, and apply a fixed-point theorem to ensure existence and a computational method. We take $e$ to be a parameter throughout. In particular, the functional space and the operator will depend on $e$. The proof requires an assumption which represents a joint restriction on the process for $Q_{i, t+1}$ and the legal ratio. In the special case, analyzed in the previous section, where $Q_{i, t+1}=Q_{i}$, Assumption 1 becomes $e \in[\underline{e}, \bar{e}]$ (which proves, incidentally, that the assumption is not vacuous). It is clear that the stochastic analogue of the bounds we found in the certainty case must involve the properties of the shock process other than its mean.

Proposition 3. If preferences over jewelry satisfy (15) and Assumption 1 holds, then there exists an equilibrium.

\section{Numerical Simulations}

The existence proof of Proposition 3 provides us with an algorithm for computing a solution, namely, finding a fixed point of the operator defined by (29). We use log preferences over jewelry as in (15) calibrated to match 1873 data as above.

We compute equilibria under various monetary regimes: the double standard (bimetallism), gold standard and silver standard. We also consider the case of an endogenous, time-varying $e_{t}$, which can be viewed as a single standard with free minting of the other metal into trade money. The numerical method for this last case is essentially the same; however, there appears to be many fixed points, depending on the starting value $\left(d_{1}(z), d_{2}(z)\right)$ chosen. In particular, a starting value with $d_{2}(z)=\gamma d_{1}(z)$ results in an equilibrium with $e_{t}$ fluctuating around $\left(b_{2} / b_{1}\right)\left(\alpha_{2} / \alpha_{1}\right)(1 / \gamma)$. This is not 
surprising, given the multiplicity of steady states. In our numerical computations, we choose a starting value such that the mean of $e_{t}$ is the same as the constant $e$ we find in the bimetallic case. ${ }^{7}$

We also make various assumptions about the processes $\left\{Q_{i, t}\right\}$. Throughout, we assume that the vector $Q_{t}=\left[\begin{array}{l}Q_{1, t} \\ Q_{2, t}\end{array}\right]$ follows a VAR process $Q_{t}=A Q_{t-1}+\epsilon_{t}$, with $A=\left(\begin{array}{cc}0.9 & 0 \\ 0 & 0.9\end{array}\right)$. In the variance-covariance matrix of $\epsilon_{t}$, both the size of the variances and the correlation between the innovations are varied, so as to change the coefficient of variation of $Q_{i, t}$ and the correlation between $Q_{1, t}$ and $Q_{2, t}$.

We consider welfare as well as the variability of the price level. The latter is measured by the coefficient of variation (standard deviation divided by mean) of the price level $p_{t}$, compared to the coefficients of variation of the shocks to $Q_{i, t}$.

We begin with the case where the shocks to gold and silver are of the same size (that is, same coefficient of variation). Figure 7 plots price variability and welfare for positive, zero and negative correlation between silver and gold shocks. It clearly shows that bimetallism displays a more stable price level than either the gold or silver standard. Welfare under bimetallism, as Proposition 2 shows for steady states, is lower than under either standard. It appears that welfare is not very sensitive to the size of the shocks, so that the ranking of steady states (both ordinal and cardinal) varies little.

Figure 8 shows the results that obtain when the shock to one metal is 2.5 times as large as the shock to the other. The upper part of the panel corresponds to the case where the shocks to silver are larger. The ordering of price level stability across monetary regimes is what one would expect.

Figure 7 indicates that the coefficient of variation of the price level is roughly linear in the coefficient of variation of the shocks to $Q_{i, t}$ (assumed equal for the two metals). It is therefore enough to examine the ratio of the former to the latter, which one can think of as a kind of "pass-through" coefficient, expressing how much of the

7 The Matlab code is available at <http://???>. 

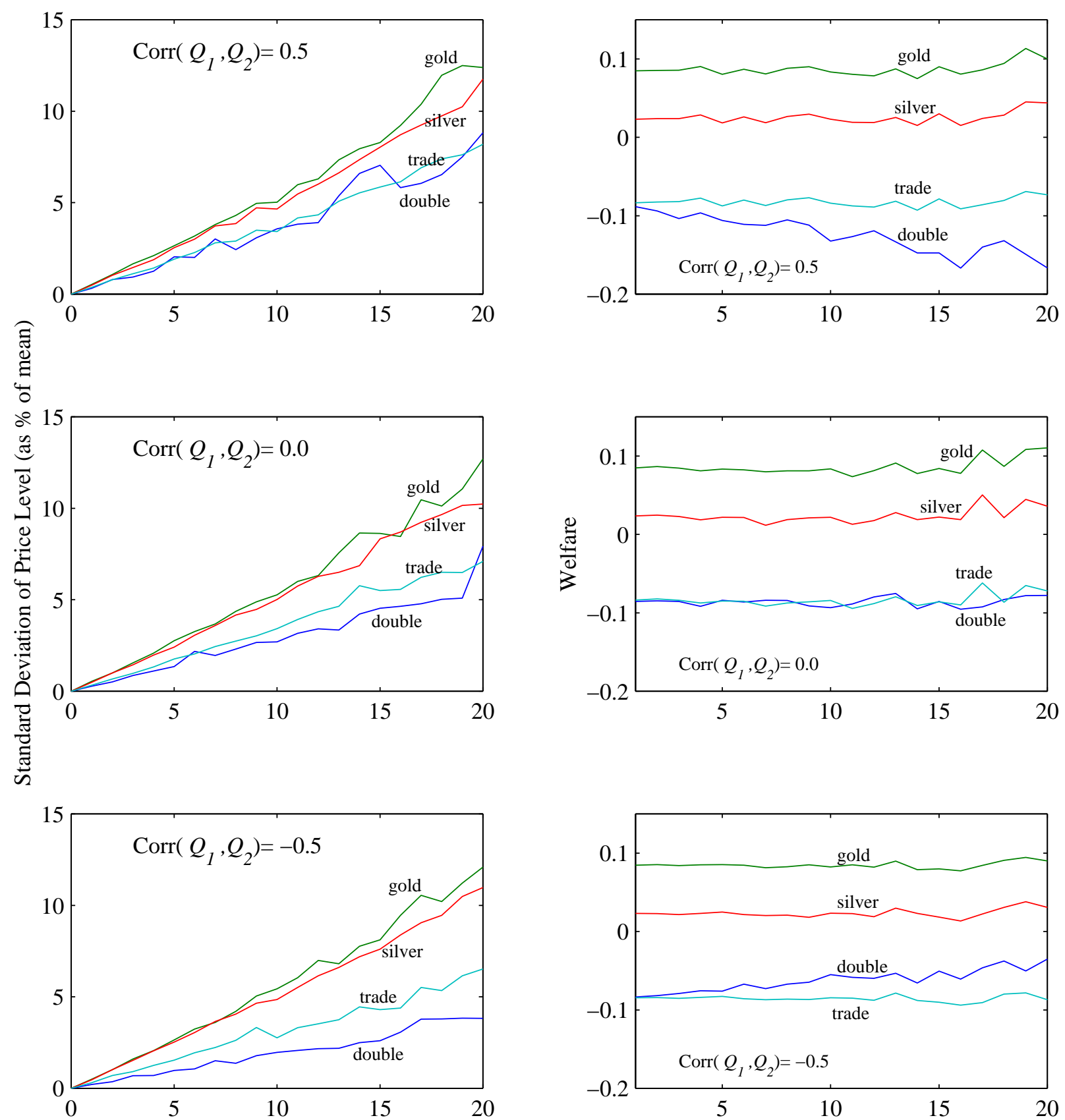

Standard Deviation of Shock to $Q_{i}$ as $\%$ of mean
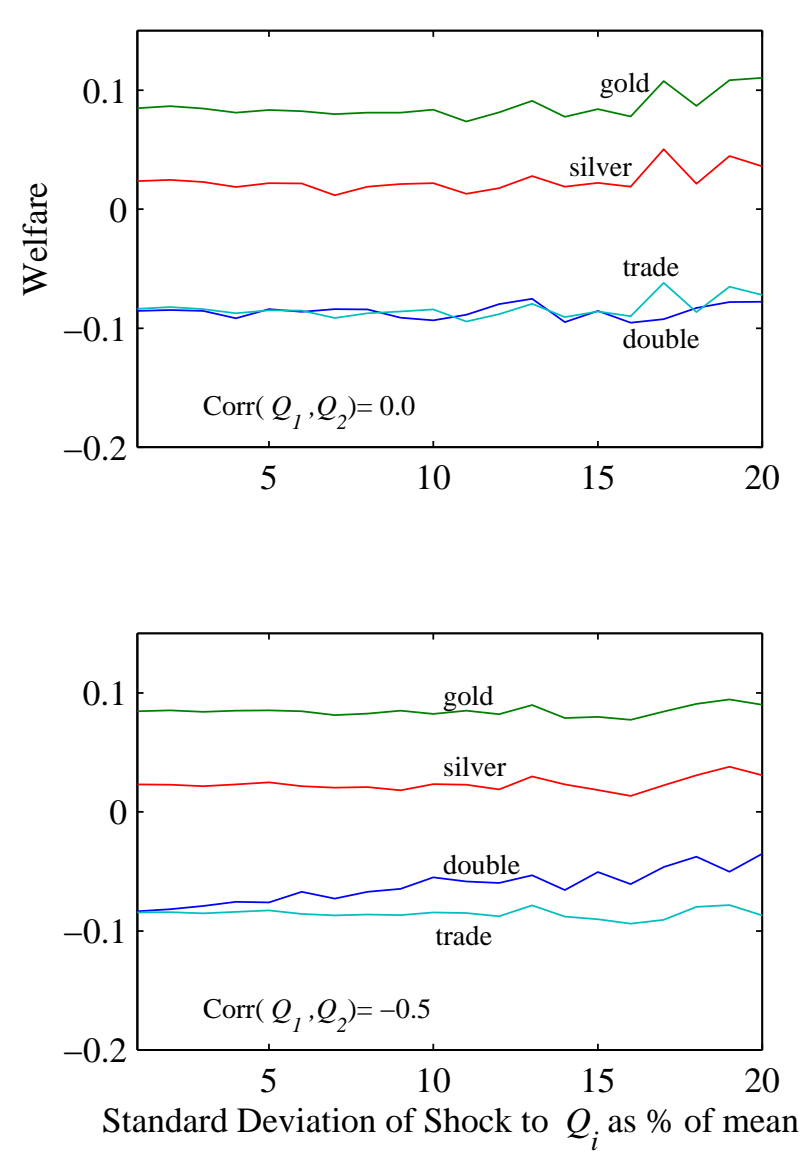

Figure 7: Variance of price level and welfare for various correlation coefficients between $Q_{1, t}$ and $Q_{2, t}$. 

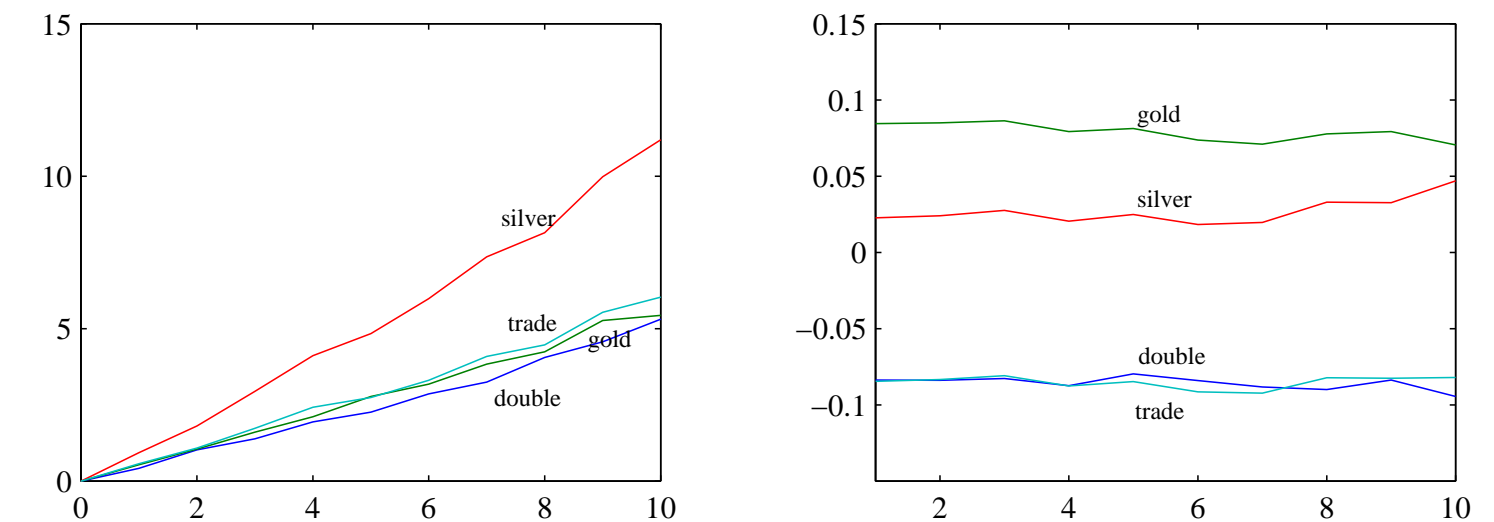

Standard Deviation of Shock to Gold as \% of mean
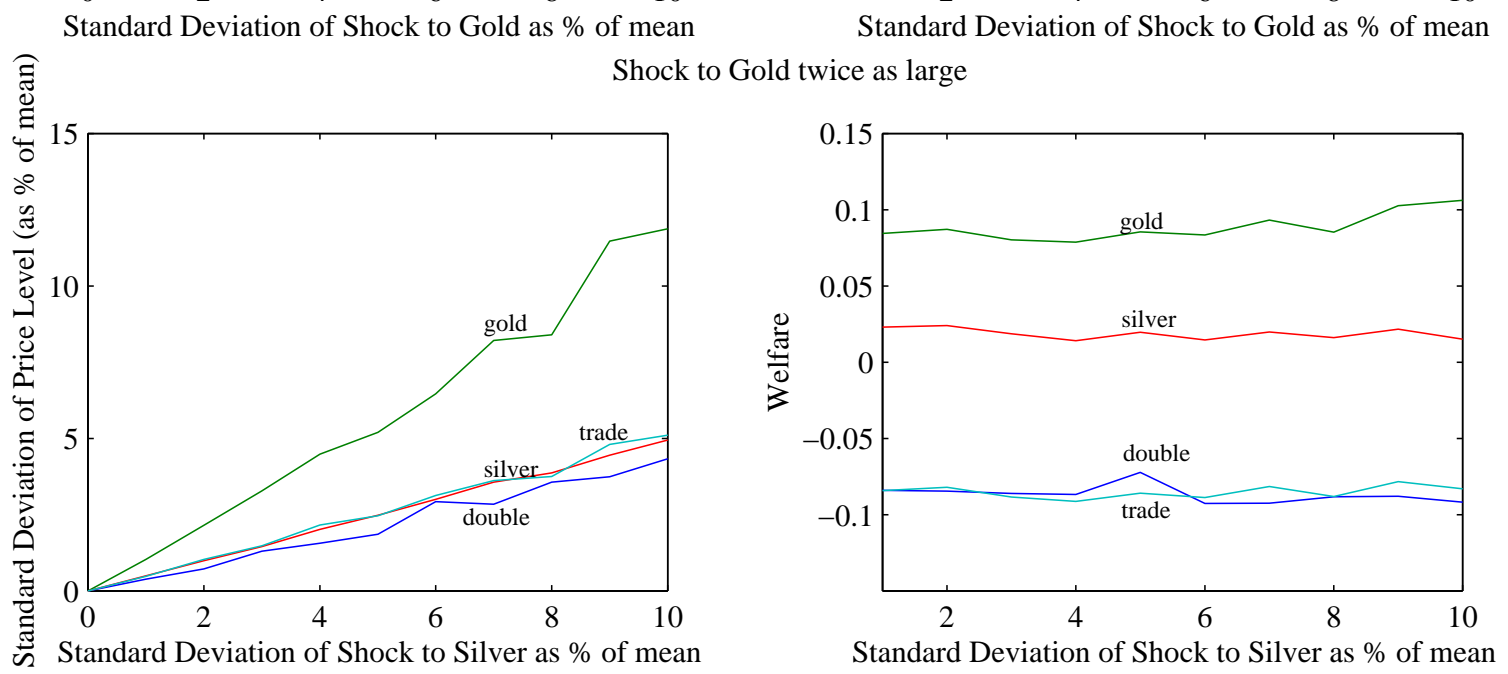

Figure 8: Variance of price level and welfare for asymmetric shocks to $Q_{1, t}$ and $Q_{2, t}$.

variability in metal stocks passes through to the price level. Figure 9 plots the average pass-through coefficient for the three monetary regimes as the correlation between gold and silver shocks varies from -0.95 to +0.95 (gold and silver shocks are assumed to be equal, and the pass-through coefficients were computed for coefficients of variation of metal shocks ranging from $1 \%$ to $20 \%$ ). Figure 9 shows, in effect, how much bimetallism reduces price level variability when compared to single standards.

As one would expect, bimetallism is most effective at stabilizing the price level when shocks to the two metals are negatively correlated. As Walras stated $(1977,359)$ : 


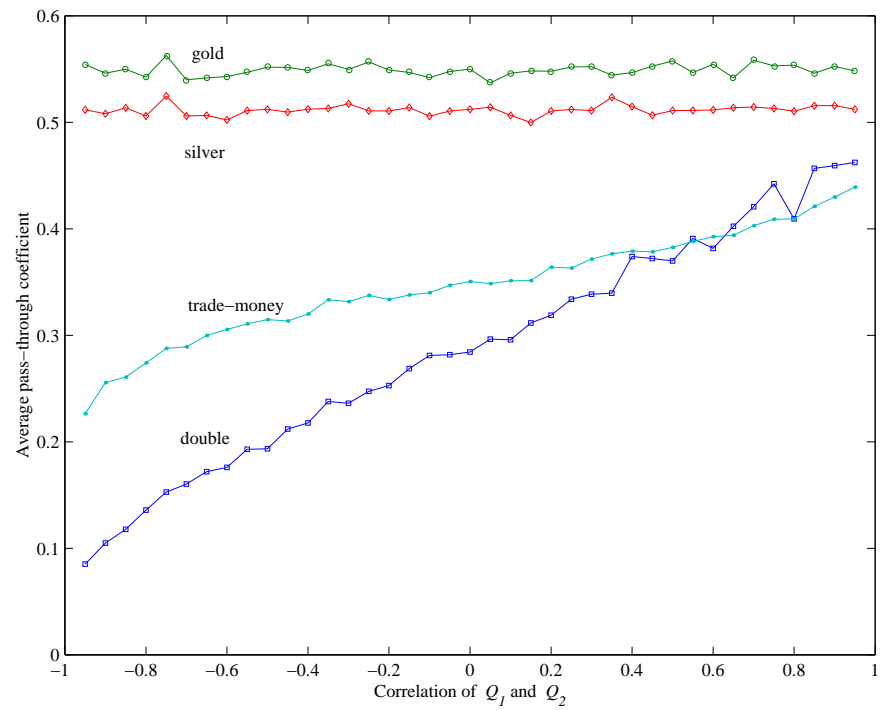

Figure 9: Pass-through coefficient (defined as ratio of the coefficient of variation of the price level to that of the shocks to metal stocks) for various degrees of correlation between the metal shocks.

"The bimetallic standard preserves a certain relative stability of value in cases where the monometallic standards would have varied in opposite directions. It varies as much as these monometallic standards in cases where they would both have moved in the same direction."

The gain over the gold standard ranges from $75 \%$ to $15 \%$. In the period $1873-$ 1913, the correlation between production shocks to the two metals was $60 \%$ : for that value of the correlation, the reduction in the coefficient of variation of the price level is about $30 \%$, when compared to the gold standard. 


\section{Positive Seigniorage: $\sigma_{i}>0$}

In this section, we consider the case with positive seigniorage. We only analyze the steady state and the dynamics under certainty. The main purpose of this section is to see to what degree seigniorage affects the model, and how the dynamics of minting and melting change with the size of the disturbances to the stocks of metal.

\section{Steady State}

When we introduce seigniorage, the analogue to (13) is:

$$
x \max \left\{\frac{1-\sigma_{1}}{v_{1}}, e^{*} \frac{1-\sigma_{2}}{v_{2}}\right\} \leq\left(Q_{1}-d_{1}\right)+e^{*}\left(Q_{2}-d_{2}\right) \leq x \min \left\{\frac{1}{v_{1}}, e^{*} \frac{1}{v_{2}}\right\}
$$

where $e^{*}=e\left(b_{1} / b_{2}\right)$ (recall that $b_{1}$ and $b_{2}$ are arbitrary) and $x=(1-\beta) u^{\prime}(\xi) \xi$. Thus, the result of introducing positive seigniorage is to "fatten" the curve in the right panel of Figure 4 as shown in Figure 10.

A necessary condition for (24) to hold is that

$$
\max \left\{1-\sigma_{1},\left(1-\sigma_{2}\right) e^{*} \frac{v_{1}}{v_{2}}\right\} \leq \min \left\{1, e^{*} \frac{v_{1}}{v_{2}}\right\} .
$$

This places bounds on the variations in the market ratio $v_{1} / v_{2}$ : it cannot vary outside of the interval $\left[\left(1-\sigma_{1}\right) / e^{*}, 1 /\left(1-\sigma_{2}\right) e^{*}\right]$. Instead of being pegged to the legal ratio, the market ratio can now fluctuate within a band around the legal ratio $1 / e^{*}$; the width of the band depends only on seigniorage rates.

In the $\log$ utility case, we can compute analytically the area in the $\left(m_{1}, m_{2}\right)$ plane that satisfies (24). Specifically, condition (24) becomes:

$\left[\left(1-\sigma_{1}\right)(1-\beta) u^{\prime}(\xi) \xi / \alpha_{1}+1\right] d_{1}+e d_{2} \leq Q_{1}+e Q_{2} \leq\left[(1-\beta) u^{\prime}(\xi) \xi / \alpha_{1}+1\right] d_{1}+e d_{2}$ $d_{1}+\left[\left(1-\sigma_{2}\right)(1-\beta) u^{\prime}(\xi) \xi / \alpha_{2}+1\right] e d_{2} \leq Q_{1}+e Q_{2} \leq d_{1}+\left[(1-\beta) u^{\prime}(\xi) \xi / \alpha_{2}+1\right] e d_{2}$ which translates into four linear inequality constraints on $d_{1}$ and $d_{2}$ for each value of $e$. In the $\left(m_{1}, m_{2}\right)$ plane, for a given $e$ these constraints define an area shown by the heavily shaded area in Figure 10. Thus, for a given $e$ there is a multiplicity of steady 


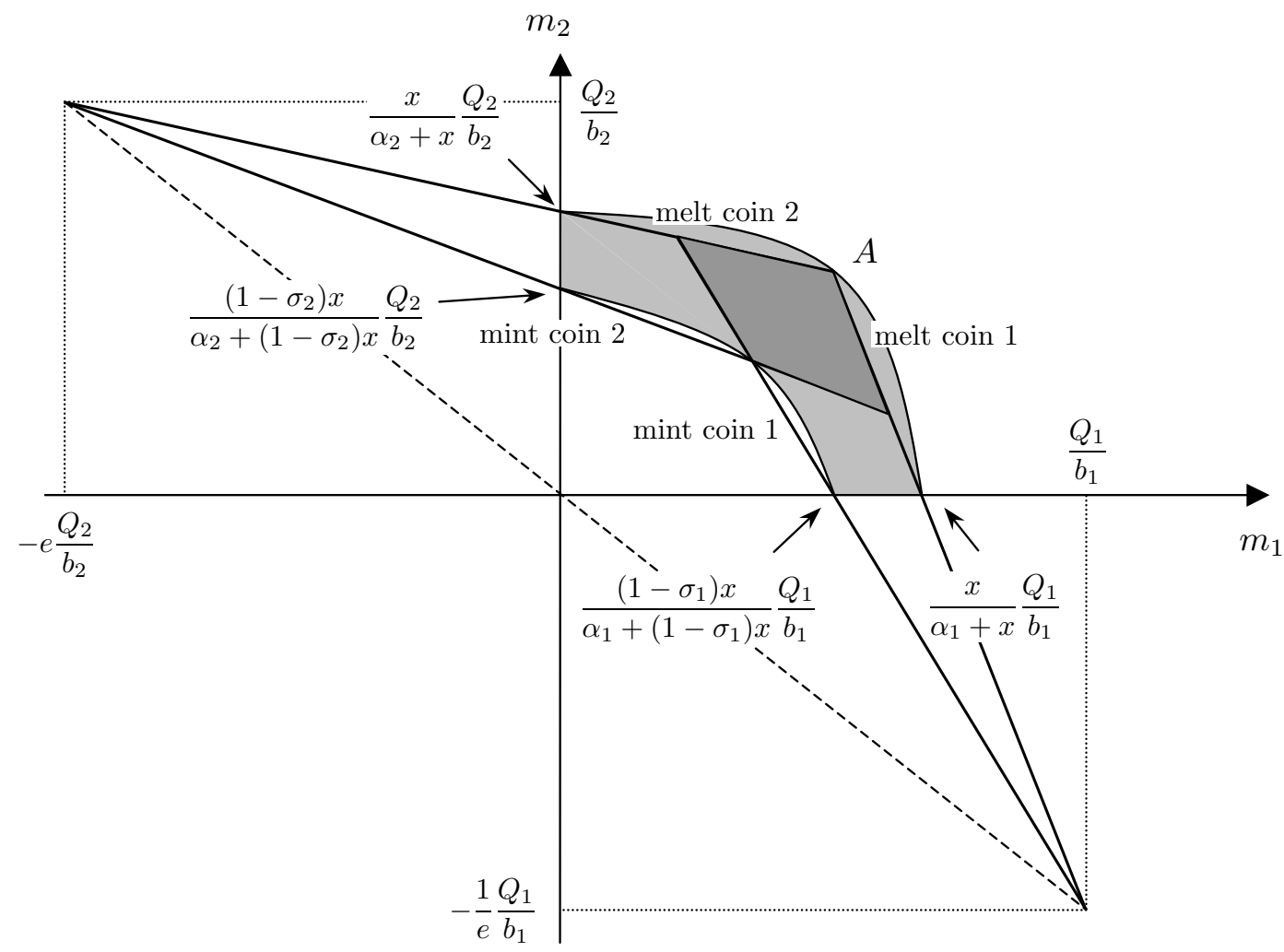

Figure 10: Locus of steady state equilibria under positive seigniorage, shown in the $\left(m_{1}, m_{2}\right)$ plane.

state equilibria, each corresponding to a different $\left(m_{1}, m_{2}\right)$. The lightly shaded area in the Figure shows for fixed stocks of the metals, the $\left(m_{1}, m_{2}\right)$ pairs that satisfy the constraint for at least one value of $e$.

Point $A$ on Figure 10 is where $e=v_{2} / v_{1}$, that is, where legal ratio and market ratio coincide. As $e$ varies, point $A$ traces a curve in the three-dimensional space $\left(m_{1}, m_{2}, e\right)$ whose projection onto the plane $\left(m_{1}, m_{2}\right)$ is exactly the hyperbola of Figure 4 .

\section{Dynamics under Certainty}

In this section, we discuss one-time changes in the stocks of metal. The mechanics of the model conform well to the intuition garnered in the zero seigniorage case, but 
go beyond, and allow a clear view of the sequence and timing of minting and melting of the two metals.

Let us assume $\xi_{t}=\xi$ and study the effect of changes in $Q_{i, t}$ over time. Out of steady state, equation (11a) will dictate the dynamics. The complete set of equations for this version of the model is:

$$
\begin{aligned}
d_{i, t+1}+b_{i} m_{i, t+1} & =d_{i, t}+b_{i} m_{i, t}+\left(Q_{i, t+1}-Q_{i, t}\right) \\
\frac{v_{i}\left(d_{t+1}\right)}{u^{\prime}(\xi)} & =\frac{q_{i, t}}{p_{t}}-\beta \frac{q_{i, t+1}}{p_{t+1}} \\
m_{1, t}+e_{t} m_{2, t} & =p_{t} \xi-q_{1, t} b_{1}\left(m_{1, t+1}-m_{1, t}\right)-q_{2, t} b_{2}\left(m_{2, t+1}-m_{2, t}\right) \\
\lambda_{t}\left(\frac{e_{t}}{e_{t+1}}-1\right) & =\frac{e_{t}}{e_{t+1}} \nu_{2, t}-\nu_{1, t} \\
\frac{1-\sigma_{1}}{b_{1}} & \leq q_{1, t} \leq \frac{1}{b_{1}} \\
\frac{e_{t}\left(1-\sigma_{2}\right)}{b_{2}} & \leq q_{2, t} \leq \frac{e_{t}}{b_{2}}
\end{aligned}
$$

We consider a one-time change in $Q_{1, t_{0}}$, the existing stock of bullion of metal 1. Assume that the economy was in steady state for $t \leq t_{0}$, and that it will be in a new steady state for $t \geq t_{0}+1$; values of the variables in the new steady state will be denoted by a tilde ${ }^{\sim}$ when they differ from the old steady state. We consider progressively larger changes. In each case, we compute the new steady state values, then use (26b) to compute the price of metal in $t_{0}$ and check whether it is within the bounds imposed by $(26 e)$ or $(26 f)$, or equal to one of the bounds.

First, consider changes in $Q_{1, t}$ that are compatible with no minting. This means that the whole change in $Q$ is absorbed by jewelry, that is, $\tilde{d}_{1}=d_{1}+\Delta Q_{1}$. In the new steady state, $m_{1}$ and $m_{2}$ are unchanged, so $p$ is unchanged, and

$$
\tilde{q}_{1}=\frac{p}{1-\beta} \frac{v_{1}\left(d_{1}+\Delta Q_{1}, d_{2}\right)}{u^{\prime}(\xi)} .
$$

Using (26b) written at $t=t_{0}$, we find that

$$
q_{1, t_{0}}=\beta \frac{\tilde{q}_{1}}{p}+\frac{v_{1}\left(d_{1}+\Delta Q_{1}, d_{2}\right)}{u^{\prime}(\xi)}=\tilde{q}_{1} .
$$


Writing (26e) at $t=t_{0}$, we find:

$$
\frac{1-\sigma_{1}}{b_{1}} \leq \frac{1}{1-\beta} \frac{v_{1}\left(d_{1}+\Delta Q_{1}, d_{2}\right)\left(m_{1}+e m_{2}\right)}{u^{\prime}(\xi) \xi} \leq \frac{1}{b_{1}}
$$

This places upper and lower bounds on $\Delta Q_{1}$. If $\Delta Q_{1}$ exceeds those bounds, then either minting (for $\Delta Q_{1}>0$ ) or melting occurs.

When minting occurs, the new steady state has same $m_{2}$ but a different $\tilde{m}_{1}$ which will have to be computed. Let $\tilde{m}_{1}=m_{1}+\Delta m_{1}$. The new stock of jewelry is

$$
\tilde{d}_{1}=d_{1}+\Delta Q_{1}-b_{1} \Delta m_{1}
$$

the price level is $\tilde{p}=\left(\Delta m_{1}+m_{1}+e m_{2}\right) / \xi$, and

$$
\tilde{q}_{1}=\frac{\tilde{p}}{1-\beta} \frac{v_{1}\left(\tilde{d}_{1}, d_{2}\right)}{u^{\prime}(\xi)} .
$$

At $t_{0}$, by assumption $q_{1, t_{0}}=\left(1-\sigma_{1}\right) / b_{1}$ and $p_{t_{0}}$ is found with equation $(26 c)$ :

$$
p_{t_{0}}=\frac{1}{\xi}\left[m_{1}+e m_{2}+\left(1-\sigma_{1}\right) \Delta m_{1}\right]
$$

Equation $(26 b)$ written at $t_{0}$ now gives

$$
\frac{1}{1-\beta} \frac{v_{1}\left(\tilde{d}_{1}, d_{2}\right)}{u^{\prime}(\xi)}=\frac{1-\sigma_{1}}{b_{1} p_{t_{0}}}
$$

or

$$
\left(1-\sigma_{1}\right)(1-\beta) u^{\prime}(\xi) \xi=v_{1}\left(d_{1}+\Delta Q_{1}-b_{1} \delta m_{1}, d_{2}\right) b_{1}\left[m_{1}+\left(1-\sigma_{1}\right) \Delta m_{1}+e m_{2}\right]
$$

which is an equation in $\Delta m_{1}$ and $\Delta Q_{1}$ : for each value of the latter, we can solve for the value of the former. The elasticity of the stock of money $m_{1}$ to a supply shock to $Q_{1}$ can be computed to be

$$
\left[\frac{b_{1} m_{1}}{Q_{1}}-(1-\sigma) \epsilon_{1} \frac{d_{1}}{Q_{1}} \frac{m_{1}}{m_{1}+e m_{2}}\right]^{-1}
$$

where $\epsilon_{1}$ is the elasticity of demand for jewelry of type 1 . 
When the supply shock is large enough to induce minting, the money supply changes, and so does the price level: this means that the price of the other metal increases as well. For large enough values of $\Delta Q_{1}, q_{2, t_{0}}$ will reach its upper bound in $(26 f)$, that is, the melting point for metal 2. This leads to the third possible case, minting of 1 and melting of 2 . Following the same procedure, $\Delta m_{1}$ and $\Delta m_{2}$ are found to be the solutions to

$$
\begin{aligned}
\left(1-\sigma_{1}\right)(1-\beta) u^{\prime}(\xi) \xi & =v_{1}(\tilde{d}) b_{1}\left[m_{1}+\left(1-\sigma_{1}\right) \Delta m_{1}+e\left(m_{2}+\Delta m_{2}\right)\right] \\
(1-\beta) u^{\prime}(\xi) \xi & =v_{2}(\tilde{d}) \frac{b_{1}}{e}\left[m_{1}+\left(1-\sigma_{1}\right) \Delta m_{1}+e\left(m_{2}+\Delta m_{2}\right)\right]
\end{aligned}
$$

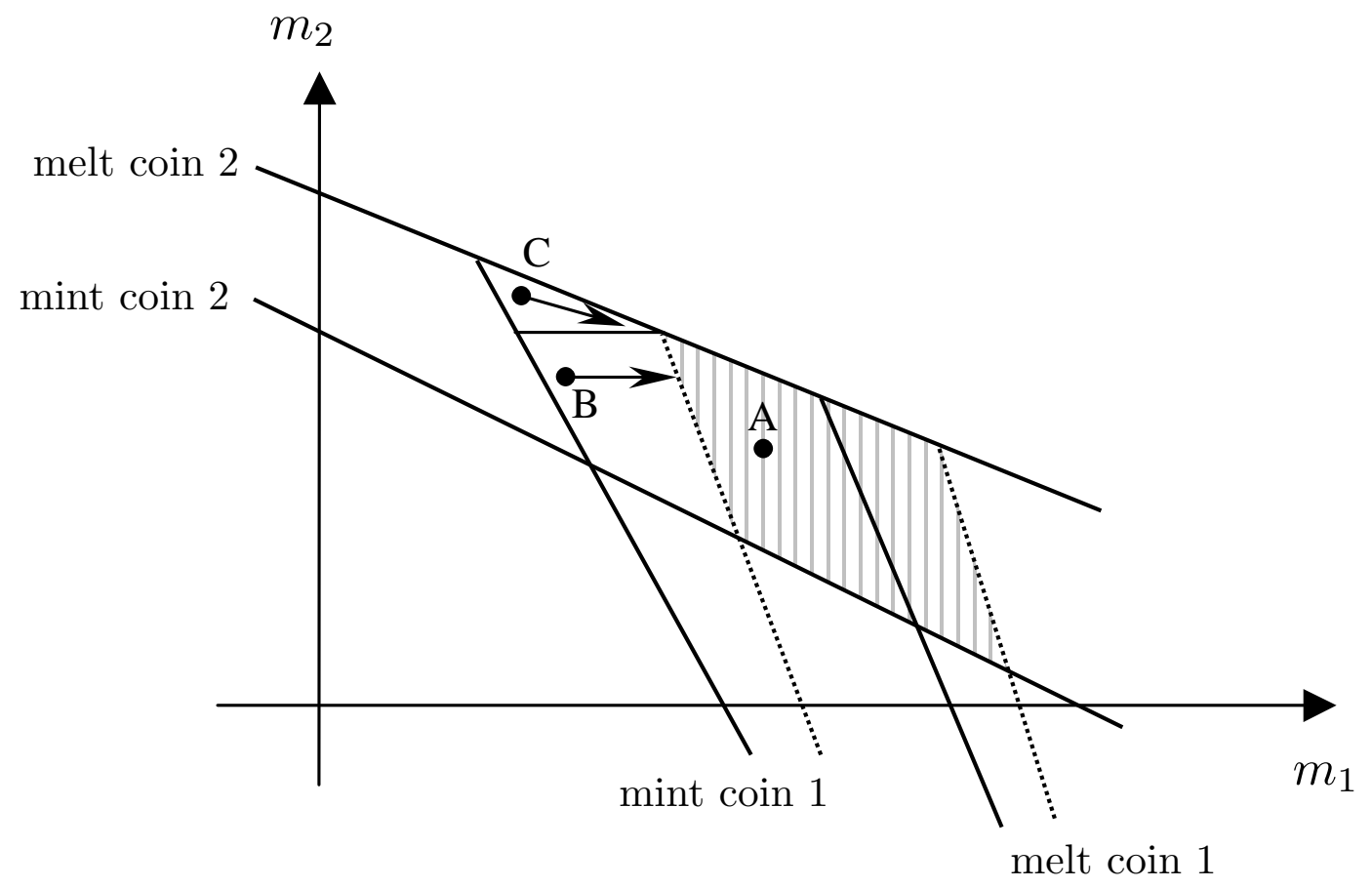

Figure 11: Effect of a permanent increase in $Q_{1}$.

The market ratio is now $\left(1-\sigma_{1}\right) / e^{*}$, which is the ratio of the mint price of gold to the mint equivalent of silver. It is kept fixed at that value for any $\Delta Q_{1}$ : this means that, while $d_{1}$ increases (because only part of the increase in gold is minted), $d_{2}$ 
increases as well, at the appropriate rate to maintain a constant market ratio, at the lower bound of the interval defined by (25).

Figure 11 illustrates these three possibilities (small, medium or large increase in $Q_{1}$ ) in terms of a diagram similar to Figure 10 . The diamond formed by the solid lines in Figure 11 is the locus of possible $\left(m_{1}, m_{2}\right)$ pairs that could be equilibria for the initial stocks of $Q_{1}$ and $Q_{2}$. The effect of an increase in $Q_{1}$ is to shifts minting and melting lines of coin 1 to the right, so that the new locus of possible $\left(m_{1}, m_{2}\right)$ equilibria is given by the shaded area.

Now suppose that the initial equilibrium in the economy was given by point like point A. Since this point also lies in the shaded area, this point is also an equilibrium after the increase in $Q_{1}$. Thus, although the increase in $Q_{1}$ decreases the market ratio, it does not move it to the point where minting of metal 1 would occur, and there is no effect on the money supplies. This would correspond to the case of a small increase in $Q_{1}$.

However, if the initial equilibrium were at point like point $\mathrm{B}$, this point is no longer an equilibrium after increase in $Q_{1}$. The above results show that the economy will move to the new equilibrium by minting some of the increase in $Q_{1}$, leading to an increase in the supply of $m_{1}$, a horizontal rightward move in Figure 11 shown by the arrow from point B..

The third case occurs when the initial equilibrium is at a point like point $\mathrm{C}$, a point which once again is not an equilibrium after the increase in $Q_{1}$. In this case, however, the economy cannot reach the shaded region by moving horizontally from $\mathrm{C}$. Instead, the melt-coin2 line is reached before the shaded area is, so that some of coin 2 is melted as some metal 1 is minted.

\section{Dynamics under Uncertainty}

The intuitions from the previous section permit us to envision what the properties of the model will be under uncertainty. For small shocks to either metal, only jewelry will vary; the stocks of money will be constant and the price level unaffected. 
For large enough shocks, one or both money stocks will change; when both metal stocks change, the behavior of the variables will be much as in the zero-seigniorage case.

The effect of seigniorage, then, is to make the price level even smoother: only the larger shocks will have any effect. Of course, the gains of smoothing the smallest variations might not be that important. In terms of welfare, there is no reason to expect the welfare rankings to be overturned.

\section{Conclusion}

Giffen, a strong opponent of bimetallism which he called "rotten throughout, and of bastard origin altogether" (Giffen 1892, 113), made very clear his theory of money: "a particular commodity is selected to perform the function of a common measure of value; but it is and remains a commodity. . . Gold remains gold, silver remains silver, cattle remain cattle, and so on, while they perform this function of money; and they remain subject to exactly the same laws of exchange after they are used as money as before" (p. 194). Thus, "gold and silver being commodities subject to different conditions of production and demand, the declaration by law or custom that a bargain may be made in one or the other at a ratio, necessarily means that, except at a moment when the market ratio may happen to coincide with the legal ratio, the bargain will be understood to be made in the metal which may be obtained at a cheaper rate than the ratio" (p. 203). One way to read Giffen is with a standard general equilibrium model, in which one, and only one numeraire may be chosen. Bimetallism, in this model, is an attempt to set two numeraires.

In our model, we give bimetallism a chance. To do this, we rely on the cash-inadvance assumption. We know that this departure from standard general equilibrium gives positive value to otherwise worthless fiat money. In a commodity money model, where "conditions of production and demand" are applicable, it gives rise to enough multiplicity that bimetallism becomes feasible. The cash-in-advance assumption, which

embodies the assumptions of the "quantitative theory of prices," thus allows us to formalize Fisher's view of bimetallism. Interestingly, we are also able to recover Walras' 
conclusion that bimetallism has one more unknown than equations. Walras, the father of general equilibrium, thus sides against Giffen.

The model delivers many assertions and insights of the bimetallist literature: the multiplicity of equilibria suggests that the government can indeed stabilize the market ratio around any legal ratio it chooses, and movements in and out of bullion will serve to maintain equality between the two ratios. We also find that the price stabilization effects are present, as emphasized by Friedman and Fisher, and are able to quantify them (see Edgeworth 1897 for an early attempt at the same goal). Our most novel finding, which could not be made outside of a properly specified general equilibrium model, is that bimetallism is always dominated by one or the other single standard, and the welfare loss is quantitatively significant.

One obvious extension is to estimate the model, rather than calibrate it, and test it properly. Beyond that, there are many open questions: we need a multi-country version of the model to address the controversies more fully. In particular, we do not provide a good explanation for the simultaneous abandonment of bimetallism by so many countries in 1873. One approach might be to embed the choice of standard in a simple game, since many explanations of the events of 1873 have the flavor of non-cooperative game theory. 


\section{Appendix 1}

Let the exogenous state $z=Q_{1} / b_{1}+e Q_{2} / b_{2}$ take values in $Z=[\underline{z}, \bar{z}]$ according to the probability distribution $\pi\left(z, d z^{\prime}\right)$. The underlying stochastic processes $Q_{i}$ are assumed to take values in $\left[\underline{Q}_{i}, \bar{Q}_{i}\right]$. Define $C(Z)$ to be the space of bounded continuous functions on $Z$.

Define $f(y, x)=1 /(y-a x)$ and $g(y, x)=1 /(y-a x)-c / x$. The function $f(y, \cdot)$ is defined over $[0, y / a)$, continuous, strictly increasing, and such that $f(y, 0)=1 / y$ and $\lim _{x \rightarrow y / a} f(y, x)=+\infty$. The function $g(y, \cdot)$ is well defined on $(0, y / a)$, continuous, strictly increasing; moreover, the following is true: $\lim _{x \rightarrow 0} g(y, x)=-\infty$ and $\lim _{x \rightarrow y / a} g(y, x)=+\infty$. Let $h(y, x)$ such that $g[y, h(y, x)]=x: h(y, \cdot)$ is welldefined on $\mathbb{R}^{+}$for all $y$, continuous, strictly increasing, with $h(y, 0)=y /(a+1 / c)$, $\lim _{x \rightarrow+\infty} h(y, x)=y / a$.

The subset on which the operator will apply is $F \subset C(Z)$, the subset of functions $d(z)$ such that $0 \leq d(z) \leq l(z)$ for all $z \in X$. The function $l(z)$, which corresponds to the restriction that $d_{i, t+1} \leq Q_{i, t+1}$, is an element of $C(Z)$ defined by

$$
d(z) \leq b_{1} \min \left\{b_{1} z-\frac{e b_{1}}{b_{2}} \bar{Q}_{2}, \frac{e b_{1}}{b_{2}} \frac{\alpha_{1}}{\alpha_{2}} Q_{2}\right\}=l(z)
$$

Clearly, $F$ is closed and bounded. To ensure that $T(F) \subset F$, we will make the following assumption.

Assumption 1. The stochastic process $\left\{Q_{1, t+1}, Q_{2, t+1}\right\}_{t \geq 0}$ and $e$ are assumed to be such that, for all $z \in X$ :

$$
\frac{1}{z-a l(z)}-\frac{c}{l(z)} \geq \beta \int \frac{\pi\left(z, d z^{\prime}\right)}{z^{\prime}-a l\left(z^{\prime}\right)}
$$

The function $l(z)$ satisfies $l(z)<z / a$. In other words, $f[z, d(z)]$ is well defined and finite everywhere for $d \in F$; moreover, by Assumption $1, E\left(f\left[z, d\left(z^{\prime}\right)\right] \mid z\right)$ is welldefined. The function $l$ has a meaningful important role: when $d(z)=l(z)$, one of the stocks of money is set to 0 , which corresponds to de facto monometallism. 
Finally, define the operator

$$
\operatorname{Td}(z)=h\left[z, \beta E\left(f\left[z, d\left(z^{\prime}\right)\right] \mid z\right)\right] .
$$

By the above arguments, $T$ is well-defined on $F$, and is clearly continuous and monotone; and for $d(z)=\overline{0}, T(\overline{0}) \geq \overline{0}$. Also, $T$ maps $F$ into itself by monotonicity of $f(y, \cdot)$ and $h(y, \cdot)$, the upper bound on all elements of $F$, and Assumption 1. It remains to show that $T(F)$ is an equicontinuous family of functions: this follows from the uniform bounds on $g(y, \cdot)$. By the Monotone Operator Theorem (Stokey and Lucas 1989, 528), $T$ has a fixed point in $F$, and the sequence $T^{n}(\overline{0})$ converges to that fixed point.

\section{Appendix 2}

Figure 3

The market ratio data is given by Soetbeer (U.S. Senate 1887). The information on the monetary systems of countries in the 19th century comes from a variety of sources, including the Reports of the Director of the U.S. Mint (various years). Countries' shares of world output are computed on the basis of the data and methods in Maddison (1995), adjusting for current borders and interpolating between the years 1820, 1870, 1900 and 1913. Not all countries are included, but those that are account for $88 \%$ of world output in 1820 and $96 \%$ in 1913.

Figures 1 and 2

The data on production of gold and silver from 1493 to 1927 come from Soetbeer's studies (U.S. Senate 1887, 76) and the papers by Ridgway and Merrill (Bureau of Mines 1929, 1930). Those figures are the ones used most commonly in the literature (Rockoff 1984, Friedman 1990; Kellenbenz 1981 assesses the Soetbeer figures). The stock of gold in 1492 is estimated from production data for gold in prior times (Quiring $1948,138,197)$ with a $1 \%$ depreciation rate assumed. The figure is 297 tons, close to an estimate of 300 tons reported by Quiring $(1948,203)$. For silver, we also use the 
production figures in prior times (Patterson 1972). Patterson gives a stock of 5,000 tons around 1300 and vague indications on the production rates in the late Middle ages. Based on these, and on Nef (1941), the rate is assumed to decline from 50 tons per year in 1300 to 15 in 1450, and to rise again to 50 by 1500. The resulting estimate of the silver stock in 1492 is 3,600 tons. Needless to say, production rates increased so much after 1492 that the stock estimates for the late 19th century are not sensitive to these assumptions.

\section{Calibration}

The numbers used for calibration of the model are as follows. Stocks in 1873 are computed as just explained. Monetary stocks of gold and silver are taken from Kitchin's estimates (League of Nations 1930, reproduced in Warren and Pearson 1933, 78; see Rockoff 1984, 621-2 for an assessment) and Drake (1985, 208) respectively. The parameters of the utility function $\alpha_{1}$ and $\alpha_{2}$ are chosen to match a legal ratio of 15.5. The values are as follows (all quantities measured in bn troy oz): $Q_{1}=0.303$, $Q_{2}=5.83, Q_{1}-d_{1}=0.138, Q_{2}-d_{2}=2.40 \alpha_{1} / x=0.0269$ and $\alpha_{2} / x=0.0360$.

\section{References}

Barro, Robert J. "Money and the Price Level under the Gold Standard." Economic Journal 89 (March 1978): 13-33.

Chen, Chau nan. "Bimetallism: Theory and Controversy in Perspective." History of Political Economy 4 (Spring 1972): 89-112.

Dowd, Kevin. "The Analytics of Bimetallism." Manchester School of Economic and Social Studies 64 (September 1996): 281-97.

Darwin, Leonard. Bimetallism: A Summary and Examination of the Arguments for and against a Bimetallic System of Currency. New York: D. Appleton \& Company, 1898. 
Drake, Louis S. "Reconstruction of a Bimetallic Price Level." Explorations in Economic History 22 (April 1985): 194-219.

Edgeworth, Francis Y. "Miscellaneous applications of the Calculus of Probabilities." Journal of the Royal Statistical Society 60 (September 1897): 681-98.

Fisher, Irving. The Purchasing Power of Money, its Determination and Relation to Credit, Interest and Crises. New York: MacMillan, 1911.

Flandreau, Marc. "As Good as Gold? Bimetallism in Equilibrium, 1850-70." In Monetary Standards and Exchange Rates, edited by Maria Cristina Marcuzzo, Lawrence H. Officer and Annalisa Rosselli. London and New York: Routledge, 1997.

Flandreau, Marc. "The French Crime of 1873: An Essay on the Emergence of the International Gold Standard, 1870-80." Journal of Economic History 56 (December 1996): 862-97.

Friedman, Milton. "Bimetallism revisited." Journal of Economic Perspectives 4 (Fall 1990a): 85-104.

Friedman, Milton. "The Crime of 1873." Journal of Political Economy 98 (December 1990b): 1154-94.

Garber, Peter M. "Nominal Contracts in a Bimetallic Standard." American Economic Review 76 (December 1986): 1012-1030.

Giffen, Robert. The Case against Bimetallism. London: George Bell \& Sons, 1892.

Kareken, John H. and Neil Wallace. "On the Indeterminacy of Equilibrium Exchange Rates." Quarterly Journal of Economics 96 (May 1981): 207-222.

Kellenbenz, Hermann. "Final Remarks: Production and Trade of Gold, Silver, Copper and Lead from 1450 to 1750." In Precious Metals in the Age of Expansion: papers of the XIVth International Congress of the Historical Sciences, edited by Hermann Kellenbenz. Stuttgart: Klett-Cotta, 1981. 
Laughlin, James Laurence. The History of Bimetallism in the U.S.. New York: D. Appleton and Company, 1896.

League of Nations. Interim Report of the Gold Delegation of the Financial Committee. Geneva, 1930. II. 26.

Maddison, Angus. Monitoring the World Economy, 1820-1992. Paris: Development Center of the OECD, 1995.

Nef, John U. "Silver Production in Central Europe, 1450-1618." Journal of Political Economy 49 (August 1948): 575-91.

Oppers, Stefan E. "A Model of the Bimetallic System." International Monetary Fund: Working Paper 95/144, 1995.

Oppers, Stefan E. "Was the Worldwide Shift to Gold Inevitable? An Analysis of the End of Bimetallism." Journal of Monetary Economics 37 (February 1996): 14362.

Patterson, C. C. "Silver Stocks and Losses in Ancient and Medieval Times." Economic History Review 2d ser., 25 (May 1972): 205-35.

Quiring, Heinrich. Geschichte des Goldes: die Goldenen Zeitalter in ihrer kulturellen und wirtschaftlichen Bedeutung. Stuttgart: Ferdinand Enke Verlag, 1948.

Redish, Angela. "The Evolution of the Gold Standard in England." Journal of Economic History 50 (December 1990): 789-805.

Redish, Angela. "The Persistence of Bimetallism in Nineteenth-Century France." Economic History Review 48 (November 1995): 717-36.

Rockoff, Hugh. "Some Evidence on the Real Price of Gold, Its Cost of Production, and Commodity Prices." In A Retrospective on the Classical Gold Standard, 18211931, edited by Michael D. Bordo and Anna J. Schwarz. Chicago: University of Chicago Press, 1984. 
Sargent, Thomas J. and Bruce D. Smith. "Coinage, Debasements, and Gresham's Laws." Economic Theory 10 (August 1997): 197-226.

Sargent, Thomas J. and François R. Velde. "The Big Problem of Small Change." Federal Reserve Bank of Chicago: Working Paper 97-8, 1997.

Sargent, Thomas J. and Neil Wallace. "A Model of Commodity Money.." Journal of Monetary Economics 12 (July 1983): 163-87.

Shaw, William Arthur. The History of Currency, 1252 to 1894. London: Wilsons \& Milne, 1896.

Stokey, Nancy L. and Robert E. Lucas, Jr. Recursive Methods in Economic Dynamics. Cambridge, MA: Harvard University Press, 1989.

U.S. Department of Commerce, Bureau of Mines. Summarized Data of Gold Production by Robert H. Ridgway, Economic Paper 6. Washington, D.C.: GPO, 1929.

U.S. Department of Commerce, Bureau of Mines. Summarized Data of Silver Production by Charles W. Merrill, Economic Paper 8. Washington, D.C.: GPO, 1930.

U.S. Senate. The International Monetary Conference of 1878. Proceedings and Exhibits, Followed by the Report of the American Commission and an Appendix Containing Correspondence Submitted to the Department of State by Mr. Fenton, and the Historical Material for the Study of Monetary Policy Contributed by Mr. Horton. 45th Cong., 3d sess., 1879. Ex. Doc. 58

U.S. Senate. Report Made by Edward Atkinson, of Boston, Mass., to the President of the United States upon the Present Status of Bimetallism in Europe. 50th Cong., 1st sess., 1887. Ex. Doc. 34

Walras, Léon. Elements of Pure Economics. Translated by William Jaffé. Fairfield, NJ: Augustus M. Kelley, 1977.

Warren, George F. and Frank A. Pearson. Prices. New York: John Wiley \& Sons, Inc, 1933. 
Willis, Henry Parker. A History of the Latin Monetary Union: A Study of International Monetary Action. Chicago: University of Chicago Press, 1901. 